\title{
Is Equipment Price Deflation a Statistical Artifact?
}

\author{
Bart Hobijn* \\ Federal Reserve Bank of New York
}

October 2001

\begin{abstract}
I argue that equipment price deflation might be overstated because the methods used to measure it rely on the erroneous assumption of perfectly competitive markets. The main intuition behind this argument is that what these price indices might actually capture is not a price decrease but the erosion of the market power of existing vintages of machines. To illustrate my argument, I introduce an endogenous growth model in which heterogeneous final goods producers can choose the technology they will use. The various technologies are supplied by monopolistically competing machine suppliers. This market structure implies that the best machines are marketed to the best workers and are sold at the highest markup. In my model economy, the endogenously determined markups are such that standard methods will tend to find equipment price deflation, even though the model does not exhibit any equipment price deflation.
\end{abstract}

keywords: imperfect competition, price indices, vintage capital.

JEL-code: O310, O470, C190.

${ }^{*}$ Correspondence: Federal Reserve Bank of New York. Domestic Research Function. 33 Liberty Street, 3rd floor. New York, NY 10045. E-mail: bart.hobijn@ny.frb.org. The views expressed in this paper do not necessarily reflect those of the Federal Reserve Bank of New York, nor those of the Federal Reserve System.

Comments by Hielke Buddelmeijer, Boyan Jovanovic and Kevin Stiroh have been crucial when writing this paper. I am indebted to seminar participants at the FRBNY and IZA for their comments and suggestions. 


\section{Introduction and motivation}

Many recent studies argue that one of the main driving forces behind the economic expansion of the 1990's is the productivity growth in the information technology producing sectors. Virtually all of these studies, including Oliner and Sichel (2000), Gordon (2000), Jorgenson and Stiroh (2000), and Violante, Ohanian, Ríos-Rull, and Krusell (2000) argue that the productivity growth in the IT producing sectors is reflected in the steady decline of their output prices relative to GDP or consumption goods. Their argument is similar to that of Greenwood, Hercowitz and Krusell (1997), who like to refer to it as investment specific technological change. Namely, if the productivity growth rate of the investment goods producing sector is consistently higher than that of the final goods producing sector, then this will lead to a steady decline in the relative price of investment goods.

If all markets would be perfectly competitive, as is assumed by all growth accounting studies referred to above, then this suggests that productivity growth in the IT producing sectors outpaces that of the consumption goods sector. This is a big if, however. Because, if these markets would be perfectly competitive then none of the IT producers would be able to make the profits necessary to recoup the expenses they made on research and development of their products ${ }^{1}$.

What I will show in this paper is that the measurement techniques used by the Bureau of Labor Statistics (BLS) and the Bureau of Economic Analysis (BEA) used to construct these investment price indices are likely to overestimate investment price deflation. The reason for this is that these methods, i.e. hedonic price methods and matched-model price indices, implicitely also assume perfectly competitive markets. The conventional assumption is that relative price declines in existing vintages when a new vintages enters the market are due to obsolescence, in the sense that the existing vintages become less productive relative to the frontier. In that case, relative price declines can be used as a measure of quality improvements and technological progress. In this paper I argue that in a market in which there is imperfect competition between the suppliers of the various vintages these relative price declines reflect two things. The first is the conventional obsolescence effect. The second is an erosion of market power of the older vintages. That is, the

\footnotetext{
${ }^{1}$ That these expenses are often substantial can be seen from Intel's and HewlettPackard's $\$ 2$ billion in expenses for the development of the Itanium chip, to come on the market in 2001. (Source: BusinessWeek, October 15, 2001, page 84)
} 
existence of better vintages erodes the market power of the supplier of an older vintage. This reduces his ability to charge markups on his product, leading this supplier to reduce its price in reaction to the introduction of better vintages by its competitors.

My argument basically consists of two steps. In the first step I argue that imperfect competition causes markups in a market to be positively correlated with the quality that the various vintages embody. The second step consists of the argument that this positive correlation will cause the BLS and BEA to overestimate equipment price deflation. I have chosen to divide this paper into two parts, each addressing one of these steps.

In the first part, consisting of section 2, I address the second step. That is, I show how a positive correlation between markups and the quality embodied in the different vintages will bias the price indices constructed by the BLS and BEA to find too much price deflation. I illustrate this point using an empirical example for PC microprocessor chips. This part is basically self-contained and can be read without reference to the theoretical model introduced in the second part.

In the second part, consisting of sections 3 and 4, I address the first step and introduce an endogenous growth model in which heterogeneous consumption goods producers can choose what technology to use. The various technologies are supplied by monopolistically competing machine suppliers. This market structure, combined with capital skill complementarities, implies that the best machines are marketed to the best workers and are sold at the highest markup. The endogenously determined markups are positively correlated with the level of productivity embodied in a machine. I use this model to show how in a world where there is no technological progress or price deflation in the machine producing sector ${ }^{2}$, the methods applied by the Bureau of Labor Statistics as well as the Bureau of Economic Analysis for the construction of the Producer Price Indices and Investment Price Indices will tend to find a steady decline in the relative price of investment goods similar to that observed in the data. In my theoretical model this measured productivity growth is completely spurious, however, and is induced by the structure of the varying markups across different vintages of machines.

My analysis in this paper distinguishes itself from the previous literature in three ways. Most importantly, it is the first to show how markups that

\footnotetext{
${ }^{2}$ In my model the average price paid and average production cost per constant quality unit (efficiency unit) of equipment are both constant over time.
} 
vary over the product cycle can cause a structural bias in measured price deflation. Secondly, the theoretical setup of monopolistic competition between suppliers of different vintages is new and deviates importantly from the conventional monopolistic competition models in the endogenous growth literature, based on Romer (1990) and Grossman and Helpman (1991). Finally, my analysis emphasizes a new dimension of markups. Previously, the empirical importance of markups had been established by Hall (1988) and the importance of their fluctuations over the business cycle had been emphasized by, among others, Woodford and Rotemberg (1999). My analysis emphasizes that their fluctuations are also important if one considers them over the product cycle. I focus on equipment prices, but my argument is equally applicable to consumer price indices. My emphasis on equipment prices is simply because these are the goods for which quality adjustments are considered most relevant.

The structure of this paper is as follows. In section 2 I show how the existence of markups affect equipment price deflation, as measured by matchedmodel and hedonic price indices. In sections 3 and 4 I introduce my endogenous growth model with imperfect competition between the suppliers of different vintages of machines that generates markups of the form that will bias equipment price indices. Section 5 is the theoretical equivalent of section 2 in the sense that I show how the pattern of equilibrium markups in my theoretical model affects matched-model and hedonic price indices. It also contains a numerical example in which I calculate the estimate equipment price deflation rates that would be measured in my theoretical model. Finally, I conclude in section 6.

\section{Markups bias equipment price inflation}

In this section I briefly review the BEA's and BLS's methods for the construction of equipment price indices and argue why varying markups over the product cycle would bias these indices. I would like to emphasize the brevity of this review and refer to Dulberger (1989) for a more extensive description of these methods. There are basically two main methods used to construct quality adjusted price indices. The first is a matched-model methodology where price indices are constructed by using the price changes for the machines that were in the market in the previous period as well as in the current one. The second are hedonic price methods where regression analysis is used 
to estimate which part of price variations can be attributed to variations in the quality of the machines in the market.

This section consists of four parts. In the first part I start by introducing the basic notation that I will use in the rest of this paper and introduce the idea of varying markups over the product cycle. In the second part, I discuss the measurement of mathed-model price indices and how they are affected by the markups. In the third part, I focus my attention on hedonic price methods. Finally, I illustrate my argument with an empirical example concerning PC microprocessor chips.

\subsection{Notation and markups}

Denote the price of a machine of vintage $v$ at time $t$ as $P_{t, v}$. Let a machine of vintage $v$ embody $A_{v}$ efficiency units of capital, where $A_{v}>A_{v-1}$ such that there is technological progress over time. Furthermore, let vintage age, denoted by $\tau$, be given by the difference between the time the vintage was introduced, i.e. $v$, and the current period, such that $\tau=t-v$. Implicit in this notation is that I will assume that in each period (at maximum) one new vintage is introduced. I will denote the number of machines of vintage $v$ sold at time $t$ as $X_{t, v}$. The implicit assumption in the vintage capital literature is that when $\bar{P}_{t}$ represents the average price level, then

$$
P_{t, v}=\bar{P}_{t} A_{v} \exp \left(u_{t, v}\right)
$$

such that, up to the stochastic term $u_{t, v}$, prices are proportional in the quality that is embodied in the machines. Implicit in this assumption is that there are no markups and that prices reflect marginal (as well as average) production costs which are assumed to be constant per efficiency unit. In this case,

relative prices reflect relative quality differences between different vintages, in the sense that

$$
\left(\ln P_{t, v}-\ln P_{t, v^{\prime}}\right)=\left(\ln A_{v}-\ln A_{v^{\prime}}\right)-\left(u_{t, v}-u_{t, v^{\prime}}\right)
$$

In this paper I argue that, instead of (1), a market with monopolistic competition between the suppliers will naturally lead to a price schedule that satisfies

$$
P_{t, v}=\mu_{t, v} \bar{P}_{t} A_{v} \exp \left(u_{t, v}\right)
$$


where $\mu_{t, v}$ is a measure of market power, which I will freely interpret as a markup in the following ${ }^{3}$. Suppliers of superior machines have more market power than suppliers of older ones. For example, the supplier of a superior machine could in principle decide to charge the same price as that of an inferior one and wipe out all the demand for its competitor. Consequently, $\mu_{t, v}>\mu_{t,(v-1)}$ and is thus positively correlated with the level of technology embodied in the various vintages of machines. This implies that the price per efficiency unit, i.e. $P_{t, v} / A_{v}$ is increasing in $v$. The purpose of an equipment price index in this economy would basically be to measure the path of the average price paid per efficiency unit, i.e. $\bar{P}_{t}$. The BLS and BEA generally apply two methods for the approximation of the path of $\bar{P}_{t}$, namely matchedmodel and hedonic methods. I will discuss the behavior of these methods under (1) and the alternative (2) below and will show that if (2) is the true underlying data-generating process, then these methods might overestimate the decline in $\bar{P}_{t}$ over time.

\subsection{Matched-model indices}

Matched model indices measure the equipment price inflation rate as a weighted average of the percentage price increases in the prices of the models of machines that were in the market both in the current measurement period as well as the previous one. Denote $P_{t}^{M}$ as the matched-model price index in this economy, then

$$
P_{t}^{M}=\left(1+\pi_{t}^{M}\right) P_{t-1}^{M}
$$

where equipment price inflation, i.e. $\pi_{t}^{M}$, equals

$$
1+\pi_{t}^{M}=\sum_{v \in \mathbf{M}} \omega_{t, v}\left(\frac{P_{t, v}}{P_{t-1, v}}\right)
$$

where $\mathbf{M}$ is the set of vintages of machines sold in the market both in the current as well as in the previous measurement period. The weights, $\omega_{t, v}$, depend on the type of price index chosen. My argument is completely independent on the choice of the weights $\omega_{t, v}$.

Suppose that (1) holds and, additionally, that the $u_{t, v}$ 's are independent,

\footnotetext{
${ }^{3}$ This is not a proper markup because it does not depend on production costs. It has, however, a similar interpretation in the sense that it is a measure of market power.
} 
both across vintages as well as over time, and $E\left[e^{u_{t, v}}\right]=E\left[e^{-u_{t, v}}\right]=1^{4}$, then the expected value of the measured equipment price inflation equals

$$
E\left[\pi_{t}^{M}\right]=\sum_{v \in \mathbf{M}} \omega_{t, v} E\left[\frac{P_{t, v}}{P_{t-1, v}}-1\right]=\frac{\bar{P}_{t}}{\bar{P}_{t-1}}-1
$$

where I have assumed, for simplicity, that the weights $\omega_{t, v}$ do not depend on the prices. In this case, the matched model index is a useful method to approximate the average price increase per efficiency unit.

If, however, (2) holds instead of (1) then

$$
E\left[\pi_{t}^{M}\right]=\sum_{v \in \mathbf{M}} \omega_{t, v} E\left[\frac{P_{t, v}}{P_{t-1, v}}-1\right]=\sum_{v \in \mathbf{M}} \omega_{t, v} \frac{\mu_{t, v}}{\mu_{t-1, v}} \frac{\bar{P}_{t}}{\bar{P}_{t-1}}-1
$$

and the estimated equipment price deflation is not an unbiased estimate of the average price increase per efficiency unit. In fact, the estimated investment price deflation is also going to depend on the rate at which the market power of each vintage erodes, i.e. on the average ratio $\mu_{t, v} / \mu_{t-1, v}$. As I will argue in the rest of this paper, in case of technological progress, i.e. an increasing $A_{v}$, the market power of a supplier of a particular vintage will erode in the sense that he will be able to charge lower markups over time, such that $\mu_{t, v} / \mu_{t-1, v}<1$. Consequently, measured equipment price deflation $\pi_{t}^{M}$ overestimates actual equipment price deflation. Moreover, the faster technological progress, the faster the erosion of market power, i.e. the smaller $\mu_{t, v} / \mu_{t-1, v}$. Hence, this bias is likely to be highest for goods for with the highest rate of embodied technological change, like the PC microprocessors that I study in my empirical example later in this section.

\subsection{Hedonic price methods}

A problem with matched-model indices is that the set $\mathbf{M}$ can be relatively small for quickly evolving product markets. An alternative is to use regression analysis methods to attribute part of price variations to observed variations in quality indicators. This is the basis of hedonic price methods. In the following I will consider log-log hedonic regressions, though my argument also applies to level-regressions.

\footnotetext{
${ }^{4}$ For example $u_{t, v}$ is independently log normal with mean $-\sigma^{2} / 2$ and standard deviation $\sigma$.
} 
Log-log hedonic regressions are based on the assumption that we can observe a set of quality indicators for a machine, say $Q_{1, v}$ through $Q_{k, v}$, such that

$$
A_{v}=A \prod_{j=1}^{k} Q_{j, v}^{\beta_{j}}
$$

and that, at each point in time, the price level of a cross section of different machines is determined by (1). Under this assumption the log-linear regression model

$$
\ln P_{t, v}=\left(\ln A+\ln \bar{P}_{t}\right)+\sum_{j=1}^{k} \beta_{j} \ln Q_{j, v}+u_{t, v}
$$

can be used to estimate the unknown coefficients $\beta_{j}$ which measure the elasticities of efficiency units with respect to the various quality indicators. For simplicity, I will focus on the case where $k=1$, such that there is a unique indicator of quality. In that case the regression model can be written as

$$
\ln P_{t, v}=\left(\ln A+\ln \bar{P}_{t}\right)+\beta \ln Q_{v}+u_{t, v}
$$

Suppose, however, that instead of (1) the actual data generating process is (2). In that case, the true regression equation reads

$$
\ln P_{t, v}=\left(\ln A+\ln \bar{P}_{t}\right)+\beta \ln Q_{v}+\ln \mu_{t, v}+u_{t, v}
$$

where, as I have argued above, the markup variable $\ln \mu_{t, v}$ is likely to be positively correlated with the quality indicator $Q_{v}$. The problem is that $\ln \mu_{t, v}$ is unobserved. Now, if (6) is the underlying price setting schedule, but one applies the regression model based on (5), then the estimate of the elasticity, i.e. $\beta$, suffers from a standard omitted variable problem where the omitted variable is positively correlated with the explanatory variable. This means that the elasticity $\beta$ will be overestimated. If $\beta$ is overestimated, too large a part of price changes is attributed to improvements in quality rather than to changes in the average price level, $\bar{P}_{t}$, and equipment price inflation is again underestimated.

\subsection{An empirical example: PC microprocessor prices}

How relevant is the effect of markups when we look at the data? I order to address this question, I will consider a simple empirical example. The 
example that I consider is the price schedule for PC microprocessor chips, to which matched-model and hedonic methods have been applied by the BLS and by Aizcorbe, Corrado, and Doms (2000). The latter find that matchedmodel and hedonic methods yield very similar deflation rates. In my example, I will mainly focus on hedonic price methods.

PC microprocessors have two distinguishing features. First of all, their most important characteristic is their clock speed, measured in MHz. Secondly, the other distinguishing feature is the specific chip architecture used for the chip, like Intel's Pentium vs. Celeron chips. I will consider two crosssections with prices for various PC microprocessors, one for April 11, 1999 and the other for March 4, 2001. The data and their sources are given in Appendix 2.

Before I actually present the data, it is useful to think about a price schedule for microprocessors. A standard hedonic analysis would be based on the assumption that these prices follow

$$
P_{t, v}=\bar{P}_{t} Q_{\text {architecture }, v}\left(M H z_{v}\right)^{\beta} \exp \left(u_{t, v}\right)
$$

where $Q_{\text {architecture,v }}$ is a constant that is the same for chips with the same architecture, while $M H z_{v}$ is the clock speed of the chip of vintage $v$. Here $\beta$ represents the elasticity of the efficiency units embodied in a chip with respect to its clock speed. Since I will argue that hedonic methods tend to overestimate this elasticity and this elasticity is unobservable, what I will argue is that the estimate of $\beta$ based on my data will be too high relative to some upperbound value of $\beta$. What is this upperbound value? I would argue that it is 1 . That is, it is reasonable to assume that a chip that is twice as fast as another one at maximum only embodies twice as many efficiency units. In fact, $\beta$ is probably smaller than 1 because chips with twice the clock speed do not interact with peripherals and other computer components at twice the speed. In fact, the speed at which the chip interacts with other components in the computer depends more on its architecture than its clockspeed. Hence, my maintained hypothesis throughout this example will be that the true elasticity $\beta$ is smaller than or equal to one.

If this hypothesis is true, then (7) implies that the price per $\mathrm{MHz}$, i.e. $P_{t, v} / M H z_{v}$, should be non-increasing in the processor speed. Figure 1 depicts the relationship between price per $\mathrm{MHz}$ and processor speed for both of my datasets. As can be seen from the figure, contrary to what my hypothesis suggests, the price paid per $\mathrm{MHz}$ is increasing for all the processor architectures for which I have data in both of my cross sections. This suggests that 
a large part of this price schedule is determined by the markups $\mu_{t, v}$. In fact, let's assume that the true price setting schedule is

$$
P_{t, v}=\mu_{t, v} \bar{P}_{t} Q_{\text {architecture }, v}\left(M H z_{v}\right)^{\beta} \exp \left(u_{t, v}\right)
$$

instead of (7), then, apart from the stochastic term $u_{t, v}$, for processors of the same architecture relative price per $\mathrm{MHz}$ measures relative markups. That is, in that case

$$
\frac{P_{t, v} / M H z_{v}}{P_{t, v^{\prime}} / M H z_{v^{\prime}}}=\frac{\mu_{t, v}}{\mu_{t, v^{\prime}}}\left(\frac{M H z_{v^{\prime}}}{M H z_{v}}\right)^{1-\beta} \frac{\exp \left(u_{t, v}\right)}{\exp \left(u_{t, v^{\prime}}\right)}
$$

This implies that since price per $\mathrm{MHz}$ is increasing in the vintage $v$, if $\beta \leq 1$ then $\mu_{t, v}$ is indeed increasing in $v$, as I have assumed throughout my argument.

What would happen if we would apply hedonic price regressions to these data? A hedonic regression based on (7) would be a regression of the logarithm of the price on an intercept, the logarithm of the clock speed, and a set of architecture dummies ${ }^{5}$. The regression results are summarized in Table 1. The estimated elasticity is 3.46 for the 1999 data and 2.41 for the 2001 data. Both are significantly bigger than one. Such estimates would lead to a severe overstatement of the contribution of increases in clock speeds of processors to their price leading to an overestimation of their price deflation.

Is this result due to imperfect competition? I would argue that the answer to this question is affirmative. In fact, the IDG News Service article about Intel's price trimming starts off with the observation that

"Intel Corp. has shaved a few dollars off the prices of its microprocessor chips for desktop computers, part of a broader effort to accelerate the adoption of its recently launched Pentium 4 chip"

which suggests that Intel's pricing policy is partly based on the cross-vintage market power depreciation considerations that are the central point of my argument.

It is fair to mention, however, that an alternative explanation for this observed price difference is that producers charge price equal to average cost,

\footnotetext{
${ }^{5}$ The regression results that I report are normalized with respect to the frontier architecture for which no dummy is included.
} 

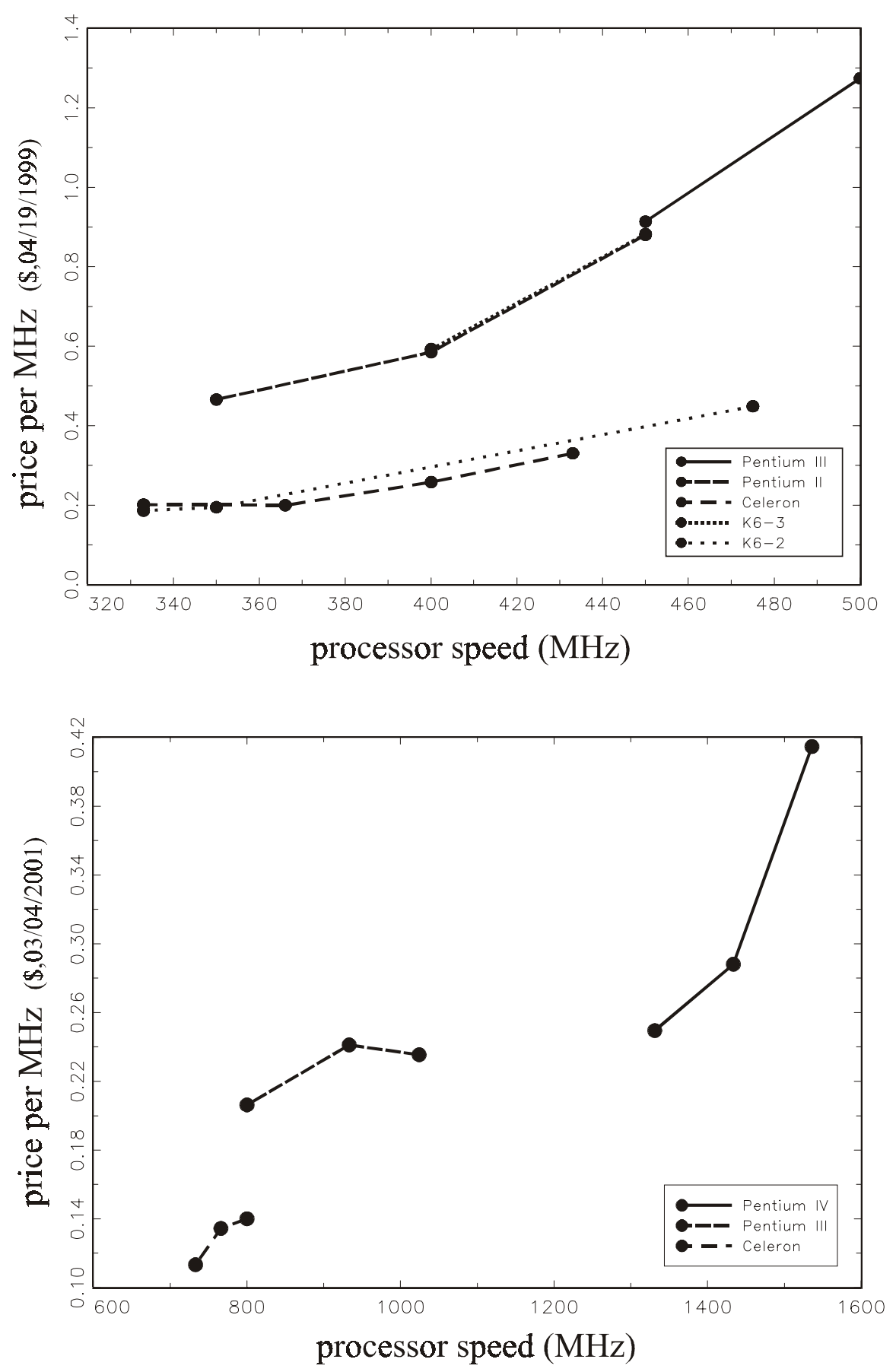

Figure 1: Price per $\mathrm{MHz}$ is increasing with speed of processor 
Table 1: Hedonic regressions for microprocessors

\begin{tabular}{|c|c|c|c|c|}
\hline \multicolumn{5}{|c|}{ dependent variable: $\ln \left(P_{t, v}\right)$} \\
\hline & \multicolumn{2}{|c|}{$04 / 11 / 1999$} & \multicolumn{2}{|c|}{$03 / 04 / 2001$} \\
\hline variable & coefficient & $t$-stat & coefficient & t-stat \\
\hline $\ln \left(M H z_{v}\right)$ & $3.46^{*, \#}$ & 16.52 & $2.41^{*, \#}$ & 3.87 \\
\hline intercept & $-15.10^{*}$ & -11.68 & -11.40 & -2.52 \\
\hline \multicolumn{5}{|c|}{ architecture dummies } \\
\hline P-III & - & - & 0.32 & 1.07 \\
\hline P-II & -0.11 & -1.41 & - & - \\
\hline Celeron & $-0.96^{*}$ & -11.23 & 0.00 & 0.00 \\
\hline K6-3 & -0.13 & -1.45 & - & - \\
\hline K6-2 & $-0.91^{*}$ & -11.22 & - & - \\
\hline$n$ & $\overline{14}$ & & 9 & \\
\hline$R^{2}$ & 0.99 & & 0.97 & \\
\hline
\end{tabular}

*: significantly different from zero at $5 \%$ significance level

\#: significantly bigger than one at $5 \%$ significance level

but that average costs of newer vintages are so much higher because of learning by doing effects. Irwin and Klenow (1994), for example, provide evidence that a doubling of cumulative past output of memory chips leads to a 20 percent drop in production costs. Since cumulative output of previous vintages is much higher than that of the newest vintage, this might explain part of the increase. One has to realize, though, that the increased marginal cost of the newest features is not only observed for capital goods, but is also observed for many consumer goods, like electronics, where it is hard to argue that learning by doing applies to the same extent. An example of such an electronics product for which markups are increasing as a fraction of price in the level of advancement of the model is the Palm Pilot. In the spring of 2001 Palm charged a price of $\$ 399$ for its high-end model, the Palm V, on which it made a profit of $\$ 150$, a $38 \%$ markup. For its low-end model, the m-100, it charged $\$ 149$ for a profit of $\$ 26$, a markup of $17 \%{ }^{6}$. There are even more striking examples of how markups affect prices. The most extreme is Cockburn and Anis (1998), who show that generic Arthritis drugs

\footnotetext{
${ }^{6}$ Source: BusinessWeek, June 4, 2001, "Palm's Market Starts to Melt Down in it's Hands"
} 
are cheaper than patented ones, even though clinical trials suggest that the generic ones are of superior quality.

\subsection{Towards a model of market power erosion}

Throughout this section I have assumed that prices follow equation (2). Where the essential difference with previous studies is the assumption of the existence of the markup variable $\mu_{t, v}$. I have argued that it is reasonable to assume that the market power of a given vintage erodes over time, such that $\mu_{t, v}>\mu_{t+1, v}$, because better vintages come online. Moreover, I have assumed that better vintages have more market power, such that $\mu_{t, v}>\mu_{t, v-1}$. In order to substantiate these assumptions I will introduce a theoretical vintage capital model, the equilibrium of which exhibits exactly these properties. This is the subject of the next two sections that follow.

\section{Market for machines}

In this section I introduce the market for machines with imperfect competition that forms the backbone of my theoretical model. This section consists of three parts. In the first part I describe the demand side of the market for machines in which workers of different types decide on their optimal technology choice. In the second part I introduce the supply side of the market in which monopolistic competitors decide on the profit maximizing price of their machines. In the third part I combine the demand and supply sides of the market and define the Pure Strategy Nash equilibrium outcome, prove its existence and uniqueness, and derive its main properties.

\subsection{Machine users}

I will take a certain degree of heterogeneity on the demand side of the market as given. This heterogeneity takes the form of different productivity types for workers. Each worker's type is denoted by $h$. I will assume there is a continuum of workers of measure one that is uniformly distributed over the unit-interval, such that $h \backsim$ unif $(0,1)$.

Final goods are produced by the combination of one worker, of type $h$, with one machine, which embodies $A_{t}$ efficiency units. The output of such 
a combination is $h A_{t}$. In order to avoid having to consider intractable intertemporal optimization problems and having to make assumptions about possible second hand markets, I will assume that machines fully depreciate in one period. This assumption basically implies that the machines considered here are equivalent to intermediate goods in the sense of Aghion and Howitt (1992) and Romer (1990). The workers can not use these machines for nothing. The price of a machine of type $A_{t-\tau}$ at time $t$ is denoted by $P_{t, \tau}$.

I will allow workers to choose the technology that they are using from a menu of available technologies. That is, workers have the choice between all the types of machines that have been introduced so far. Let $A_{t}$ be associated with the machines introduced at time $t$, then, at time $t$, the workers can choose from the 'technology-menu' $\mathbf{A}_{t}=\left\{A_{t}, A_{t-1}, \ldots\right\}$. The notational convention that I will use in this paper follows Chari and Hopenhayn (1991) in the sense that $\tau$ represents 'vintage age'. That is, $A_{t}$ represents the frontier technology level and $A_{t-\tau}$ is the frontier technology level of $\tau$ periods ago. For notational convenience, I will, every once in a while, switch between the notation of technology in its levels, i.e. $A_{t}$, and technology growth rates, i.e. $g_{t}=\frac{A_{t}-A_{t-1}}{A_{t-1}}$. Throughout, I will assume that there is no technological regress such that $g_{t}>0$ for all $t$.

In order to maximize his income, a worker of type $h$ will choose a technology from the technology choice set, $\Upsilon_{t}(h)$, which is defined as the set of vintages for which he maximizes his labor income, such that

$$
\Upsilon_{t}(h)=\left\{\tau \in \mathbb{N} \mid \tau \in \underset{s \in \mathbb{N}}{\arg \max }\left\{h A_{t-s}-P_{t, s}\right\}\right\}
$$

The resulting labor income of a worker of type $h$ at time $t$ equals

$$
y_{t}(h)=h A_{t-\tau}-P_{t, \tau}, \text { for all } \tau \in \Upsilon_{t}(h)
$$

\subsection{Machine producers}

Machine designs are assumed to be patented for $M$ periods. During the first $M$ periods of a machine design's life, the particular machine is supplied by a monopolist firm. After the patent expires the machine design is public domain and there is perfect competition in the supply of these machines. I will assume that units of the consumption good are the only input needed in machine production, this to avoid having to deal with the selection of workers across sectors. The production of a continuum of mass $X$ of machines of type 
$A_{t-\tau}$ requires the use of $\frac{c_{\tau}}{2} A_{t-\tau} X^{2}$ units of the consumption good, where $c_{\tau} \geq 0$. That is, when $c_{\tau}>0$ a machine producer faces decreasing returns to scale. Note that the cost function is scaled by $c_{\tau}$ which depends on the vintage age, in order to allow for learning by doing.

The set of buyers of machines of type $t-\tau$, which I will denote by $D_{t}(\tau)$, is given by

$$
D_{t}(\tau)=\left\{h \in[0,1] \mid \tau \in \underset{s \in\{0,1,2, \ldots\}}{\arg \max }\left(h A_{t-s}-P_{t, s}\right)\right\}
$$

As I will show in proposition 1 in the next subsection, these sets will be connected intervals of the form

$$
D_{t}(\tau)=\left[\underline{h}_{t, \tau}, \bar{h}_{t, \tau}\right]
$$

Total demand for the machine of type $t-\tau$ at time $t$ is then given by the measure of workers demanding the specific vintage, i.e.

$$
X_{t, \tau}=\left(\bar{h}_{t, \tau}-\underline{h}_{t, \tau}\right)
$$

The question that is left is how these machine producers end up choosing the prices of their machines. Throughout this paper, I will focus on Pure Strategy Nash equilibria. For the particular problem at hand here this implies that, taking the prices of the other machines, i.e.

$$
\mathbf{P}_{t, \tau}^{\prime}=\left\{P_{t, 0}, \ldots, P_{t, \tau-1}, P_{t, \tau+1}, \ldots\right\},
$$

and the levels of the technologies, i.e.

$$
\mathbf{A}_{t}=\left\{A_{t}, A_{t-1}, \ldots\right\},
$$

as given, the machine producer to type $A_{t-\tau}$ chooses the price of his machine to maximize profits. This implies that $P_{t, \tau}$ is an element of the best response set

$$
B R_{t}\left(\tau ; \mathbf{P}_{t, \tau}^{\prime}, \mathbf{A}_{t}, r_{t}\right)=\left\{P_{t, \tau} \in \mathbb{R}_{+} \mid P_{t, \tau} \in \underset{P \in \mathbb{R}_{+}}{\arg \max }\left\{P X_{t, \tau}-\frac{c_{\tau}}{2} A_{t-\tau} X_{t, \tau}^{2}\right\}\right\}
$$

Because patents expire after $M$ periods, these best response sets only apply to $\tau=0, \ldots, M-1$. For machines that were designed $M$ or more periods ago, perfect competition implies that price must equal average cost, and that free entry drives both to zero, such that $P_{t, \tau}=0$ for $\tau \geq M$. The corresponding profits are

$$
\pi_{t, \tau}=P_{t, \tau} X_{t, \tau}-\frac{c_{\tau}}{2} A_{t-\tau} X_{t, \tau}^{2} \text { for all } P_{t, \tau} \in B R_{t}\left(\tau ; \mathbf{P}_{t, \tau}^{\prime}, \mathbf{A}_{t}, r_{t}\right)
$$

for $\tau=0, \ldots, M-1$. 


\subsection{Equilibrium and its properties}

Now that the demand and supply side of the machine market are well defined, I can focus on the resulting Pure Strategy Nash equilibrium. Such an equilibrium consists of a price schedule, i.e. $\mathbf{P}_{t}^{*}=\left\{P_{t, 0}^{*}, \ldots, P_{t, M-1}^{*}\right\}$ and a collection of corresponding demand sets, i.e. $\left\{D_{t}^{*}(0), D_{t}^{*}(1), \ldots\right\}$. I will derive the equilibrium in two steps. In the first step I show that, independent of the price schedule, the demand sets $D_{t}(\tau)$ have some important properties. In the second step I use these properties to derive the equilibrium price schedule $\mathbf{P}_{t}^{*}$. This equilibrium price schedule is then used to derive equilibrium output, profits, and demand sets.

The main result of the first step is that $(i)$ better workers use better technologies, i.e. there is endogenous assortative matching between workers and machines. Models where this matching also occurred are, for example, Jovanovic (1999) and Sattinger (1975). (ii) Perfect competition implies that machines of a design for which the patent is expired for more than a year are not demanded anymore. They are obsolete. ( $i i i)$ Demand functions are properly specified in the sense that for almost all workers their technology choice is unique. ( $i v$ ) If two workers of different types buy the same vintage

of machine, then so will the workers of all types in between. These four things are formalized in Proposition 1 below, which is proven in Appendix 1.

\section{Proposition 1 Properties of demand sets}

Independent of the technology menu $\mathbf{A}_{t}$ and the price schedule $\mathbf{P}_{t}$, the demand sets $D_{t}(\tau)$ have the following properties:

(i) For $h^{\prime}>h$, if $h \in D_{t}(\tau)$ then $h^{\prime} \notin D_{t}\left(\tau^{\prime}\right)$ for all $\tau^{\prime}>\tau$.

(ii) $D_{t}(\tau)=\emptyset$ for all $\tau>M$.

(iii) Define the set of workers for whom the optimal technology choice is not unique as

$$
\widetilde{\mathcal{H}}_{t}=\left\{h \in[0,1] \mid \exists \tau \neq \tau^{\prime} \text { such that } h \in D_{t}(\tau) \wedge h \in D_{t}\left(\tau^{\prime}\right)\right\}
$$

then $\widetilde{\mathcal{H}}_{t}$ is negligible.

(iv) $D_{t}(\tau)$ is connected for all $\tau$.

The intuition behind this proposition is probably most clear when one considers a graphic example of how these demand sets are determined. Figure 2 depicts the way these demand sets are determined for the case in which $M=2$. For simplicity, the time subscript, $t$, is ignored in the figure. The top 
panel of figure 2 shows the levels of gross output, i.e. $h A_{\tau}$, that workers of different types get for the three available technologies, i.e. $\tau \in\{0,1,2\}$, the dots mark the points at which the price and gross output levels coincide. The short dashed vertical lines, that extend to the bottom panel, determine the levels of the critical types that get zero income for the various technologies. The bottom panel then depicts the net output levels, i.e. the workers income levels for the three technologies. Workers choose that technology that yields them the highest income level, which implies the demand sets plotted at the bottom.

Now that I have shown that the demand sets have some convenient properties, I can use them to derive the equilibrium price schedule. Before doing so, I first formally define the PSN-equilibrium for the prices in the machine producing sector, which is

\section{Definition 1 Equilibrium price schedule}

For a given sequence of technology levels, $\mathbf{A}_{t}=\left\{A_{t}, A_{t-1}, \ldots\right\}$, a price schedule $\mathbf{P}_{t}^{*}=\left\{P_{t, 0}^{*}, P_{t, 1}^{*}, \ldots\right\}$ is a Pure Strategy Nash equilibrium price schedule if

(i) $P_{t, \tau}^{*}=0$ for all $\tau \geq M$.

(ii) Define $\mathbf{P}_{t, \tau}^{*^{\prime}}=\left\{P_{t, 0}^{*}, \ldots, P_{t, \tau-1}^{*}, P_{t, \tau+1}^{*}, \ldots\right\}$, then $P_{t, \tau}^{*} \in B R\left(\tau ; \mathbf{P}_{t, \tau}^{*^{\prime}}, \mathbf{A}_{t}, r_{t}\right)$ for all $\tau=0, \ldots, M-1$.

What I will show in this step is that, for all possible technology paths $\mathbf{A}_{t}=\left\{A_{t}, A_{t-1}, \ldots\right\}$, there exists a unique equilibrium price schedule. This price schedule is such that all technologies of age $M$ or more recent are used. In particular, the core-proposition of this subsection reads

\section{Proposition 2 Solution of equilibrium price schedule}

For any sequence of technology levels, $\mathbf{A}_{t}=\left\{A_{t}, A_{t-1}, \ldots\right\}$, there exists a unique equilibrium price schedule with the following properties:

(i) $P_{t, \tau}>\frac{c_{\tau}}{2} A_{t-\tau} X_{t, \tau}^{2} \geq 0$ for all $\tau=0, \ldots, M-1$.

(ii) $D_{t}(\tau) \neq \emptyset$ for all $\tau=0, \ldots, M$.

(iii) The equilibrium price schedule is unique, and defining the price per efficiency unit as $\widehat{P}_{t, \tau}=P_{t, \tau} / A_{t-\tau}$, it satisfies

$\widehat{P}_{t, \tau}=\left\{\begin{array}{ccc}{\left[\frac{1+c_{0}\left(1+w_{t, 0}^{1}\right)}{2+c_{0}\left(1+w_{t, 0}^{1}\right)}\right]\left[\frac{1}{1+w_{t, 0}^{1}}+\frac{w_{t, 0}^{1}}{1+w_{t, 0}^{1}} \widehat{P}_{t, 1}\right]} & \text { for } & \tau=0 \\ {\left[\frac{1+c_{\tau}\left(w_{t, \tau}^{\tau+1}+w_{t, \tau}^{\tau-1}\right)}{2+c_{\tau}\left(w_{t, \tau}^{\tau+1}+w_{t, \tau}^{\tau-1}\right)}\right]\left[\frac{w_{t, \tau}^{\tau-1}}{w_{t, \tau}^{\tau+1}+w_{t, \tau}^{\tau-1}} \widehat{P}_{t, \tau-1}+\frac{w_{t, \tau}^{\tau-1}}{w_{t, \tau}^{\tau+1}+w_{t, \tau}^{\tau-1}} \widehat{P}_{t, \tau+1}\right]} & \text { for } & \tau=1, \ldots, M-1 \\ 0 & \text { for } & \tau=M\end{array}\right.$ 


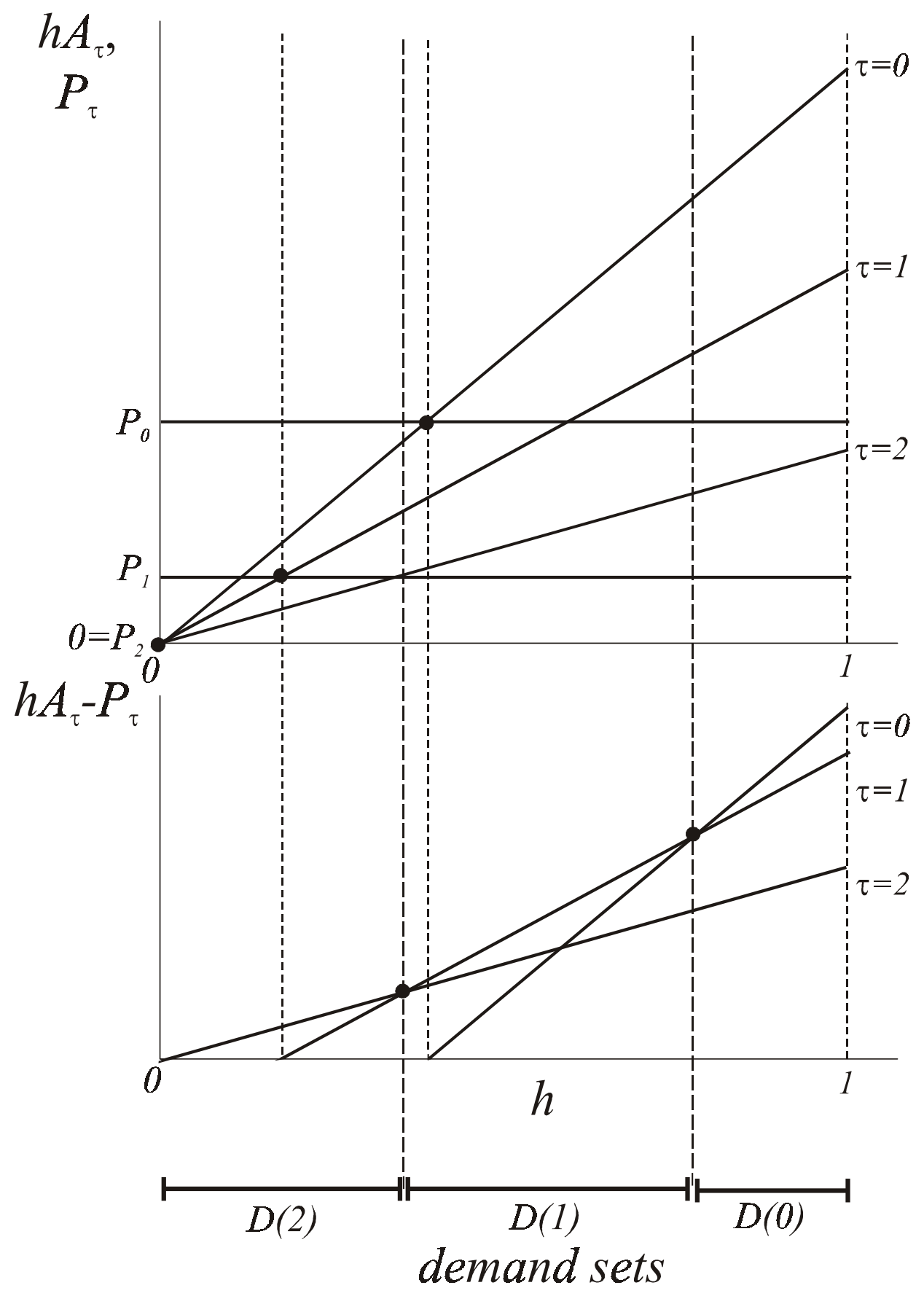

Figure 2: Determination of demand sets 
where

$$
w_{t, \tau}^{\tau-1}=\frac{A_{t-\tau+1}}{A_{t-\tau+1}-A_{t-\tau}}, \text { and } w_{t, \tau}^{\tau+1}=\frac{A_{t-\tau-1}}{A_{t-\tau}-A_{t-\tau-1}}
$$

(iv) $\widehat{P}_{t, \tau}$ is strictly decreasing in $\tau$.

(v) The demand sets satisfy

$$
X_{t, \tau}=\left\{\begin{array}{ccc}
{\left[\frac{1+w_{t, 0}^{1}}{1+c_{0}\left(1+w_{t, 0}^{1}\right)}\right] \widehat{P}_{t, 0}} & \text { for } & \tau=0 \\
{\left[\frac{\left(w_{t, \tau}^{\tau+1}+w_{t, \tau}^{\tau-1}\right)}{1+c_{\tau}\left(w_{t, \tau}^{\tau+1}+w_{t, \tau}^{\tau-1}\right)}\right] \widehat{P}_{t, \tau}} & \text { for } & \tau=1, \ldots, M-1 \\
w_{t, M}^{M-1} \widehat{P}_{t, M-1} & \text { for } & \tau=M
\end{array}\right.
$$

The proof of this proposition is again in Appendix 1. Besides the fact that this proposition proves the existence and uniqueness of the PSN-equilibrium in this market, the most important result of this proposition is (iv). It basically implies that the average cost per efficiency unit is higher for more recent vintages than for older ones. Note that this result is independent of the path of technological progress as well as the cost structure underlying production of the vintages of machines, i.e. $\left\{c_{\tau}\right\}_{\tau=0}^{\infty}$. It is simply due to the imperfect competition between the machine suppliers. This is the result that will underlie the spurious equipment price deflation result that I will present in Section 5. First, however, I will implement the market for machines introduced here in an endogenous growth model.

\section{Endogenous Growth Model}

The aim of this section is to implement the market introduced above in a general equilibrium framework with endogenous growth. In order to do so, I have to combine the machine buyers and suppliers with a final goods demanding sector, i.e. consumers, as well as with a sector that creates new machine designs and moves the technological frontier outward, i.e. an R\&D sector. These two respective additions form the first two subsections of this section. In the third subsection, I combine all sectors of the economy to define a competitive equilibrium and balanced growth path for it.

\subsection{Consumers}

Consumers and workers in the final goods sector are basically the same. I will assume that workers of all types each maximize the present discounted value 
of their lifetime utility and have constant relative risk aversion preferences, such that they choose to maximize

$$
\frac{1}{1-\sigma} \sum_{s=t}^{\infty} \beta^{s-t} c_{s}(h)^{1-\sigma}
$$

subject to their budget constraint

$$
k_{t}(h)=\left(1+r_{t}\right) k_{t-1}(h)+y_{t}(h)-c_{t}(h)+\Pi_{t}
$$

where $k_{t}(h)$ is capital holdings at period $t$ of a worker of type $h$, which is assumed to be the same for all workers of the same type, $r_{t}$ is the interest rate, $y_{t}(h)$ is the labor income of a worker of type $h$ in period $t$, and $c_{t}(h)$ is the corresponding consumption level, and $\beta \in(0,1)$ the discount factor. The income $\Pi_{t}$ is obtained from innovative activities that each household invests in, which I will explain in the subsection below.

This problem yields the familiar Euler equation

$$
\frac{c_{t+1}(h)}{c_{t}(h)}=\left[\beta\left(1+r_{t}\right)\right]^{\frac{1}{\sigma}}
$$

This implies that the consumption growth rates of all workers are the same, independent of their type. As described in Caselli and Ventura (2000), this implies that aggregate consumption is consistent with that of a representative consumer that has CRRA preferences himself.

In the following, capital letters, e.g. $Y_{t}$, denote aggregates obtained from aggregation over the various types of workers, i.e.

$$
Y_{t}=\int_{0}^{1} y_{t}(h) d h
$$

The aggregates $K_{t}, C_{t}$, and $Y_{t}$, behave as if they were the solution to a representative consumer solving a utility maximization problem that is identical to that of the workers of each type, but then defined in these aggregates.

\subsection{Patent race and innovation}

As a simplifying assumption for my general equilibrium framework, I will assume, as do Reinganum (1983), Gilbert and Newbery (1982) and Aghion and Howitt (1992), that the size of the innovation (in each period) is fixed. 
In particular, the size of the innovation is $g>0$, in the sense that $A_{t+1}=$ $(1+g) A_{t}$ for all $t$, as a result of an innovation ${ }^{7}$. Instead of the size of the innovation, what is determined in equilibrium is the R\&D intensity with which the innovation is pursued. This intensity is represented by the amount of output spent on the patent race, which I will denote by $X_{t, R}$. The final good is assumed to be the only input into the R\&D process.

If one wins the patent race, then one obtains a patent with a value that is equal to the present discounted value of the monopoly profits made on the particular machine design. I will derive this value in more detail later, but for the moment will simply denote it by $V_{t}$. It turns out to be convenient to also consider the value per efficiency unit, $V_{t}^{*}$, which satisfies $V_{t}^{*}=V_{t} / A_{t}$. The patent race that I consider is one in which the probability of winning per unit of output spent is inversely proportional to the total amount of resources devoted to R\&D, i.e. $X_{t, R}$. That is, when $X_{t, R}$ is the total amount of resources spent for R\&D purposes, the spender of a unit of output on R\&D pays a price equal to one and obtains the expected revenue $V_{t} / X_{t, R}$. I will assume that there is no advantage for the incumbent, such that incumbents and entrants have an equal chance of winning the patent race. Since there are basically $M$ incumbents and a continuum of researchers, the possibility of an incumbent winning the race is zero. Furthermore, freedom of entry and exit in R\&D implies the zero profit equilibrium condition $X_{t, R}=A_{t} V_{t}^{*}$.

So, what is left to derive is the present discounted value of the monopoly profits made off a machine design, i.e. $V_{t}$. The assumption that $g$ is constant over time implies some important simplifications for the behavior of prices, output, and the value of an innovation. These implications are derived in the proposition below.

Proposition 3 value of innovation, output, etc., at constant $g$ If the technological frontier moves out at the same rate, $g$, in each period then this implies

(i) prices: the vintage age specific prices per efficiency unit satisfy

$$
P_{t, \tau} / A_{t-\tau}=\mu_{\tau}(g, \mathbf{c})
$$

where $\mu_{\tau}(g)>\mu_{\tau+1}(g)$ for all $\tau=0, \ldots, M-1, g>0$, and $\mathbf{c}=\left\{c_{0}, \ldots, c_{M}\right\}$ is the sequence of production parameters for machines.

\footnotetext{
${ }^{7}$ Throughout, I will assume that $g<\left(\frac{1}{\beta}\right)^{\frac{1}{1-\sigma}}-1$, such that the consumer's objective function will be bounded.
} 
(ii) demand for various vintages: the demand for different vintages of machines, i.e. $X_{t, \tau}$, satisfies

$$
X_{t, \tau}=\tilde{X}_{\tau}(g, \mathbf{c})
$$

and only depends on vintage age and not on time.

(iii) output: aggregate output, $Y_{t}$, can be written as

$$
Y_{t}^{*}=Y_{t} / A_{t}=\tilde{Y}(g, \mathbf{c})
$$

(iv) profits: the vintage age specific profits follow

$$
\pi_{t, \tau}^{*}=\pi_{t, \tau} / A_{t}=\tilde{\pi}_{\tau}(g, \mathbf{c})
$$

(v) value of innovation: for the value of the innovation I will assume that the REDD costs incurred today yield a patent for a machine that comes online only in the next period. Consequently, the value of the innovation at time $t$ can be written as

$$
\begin{aligned}
V_{t}^{*} & =\sum_{s=1}^{M}\left(\frac{1}{1+g}\right)^{s-1}\left(\prod_{j=0}^{s-1}\left(\frac{1}{1+r_{t+j}}\right)\right) \widetilde{\pi}_{s-1}(g, \mathbf{c}) \\
& =V^{*}\left(r_{t}, \ldots, r_{t+M} ; g, \mathbf{c}\right)
\end{aligned}
$$

(vi) rents on innovative activities: For simplicity, I will assume that each household will take an equal share in each research project, such that there is no uncertainty about the return to their expenditures. Consequently, the income earned from innovative activities equals the sum of the flow profits made on the currently patented machine designs minus the current R\&D expenditures, such that

$$
\begin{aligned}
\Pi_{t} & =\sum_{\tau=0}^{M} A_{t-\tau} \widetilde{\pi}_{\tau}(g, \mathbf{c})-X_{t, R} \\
& =A_{t} \sum_{\tau=0}^{M}\left(\frac{1}{1+g}\right)^{\tau} \widetilde{\pi}_{\tau}(g, \mathbf{c})-A_{t} X_{t, R}^{*}
\end{aligned}
$$

where $X_{t, R}^{*}=X_{t, R} / A_{t}$.

The functions $\mu_{\tau}(g, \mathbf{c}), \widetilde{X}_{\tau}(g, \mathbf{c}), \widetilde{Y}(g, \mathbf{c})$ and $\widetilde{\pi}_{\tau}(g, \mathbf{c})$ are independent of time. 


\subsection{Competitive equilibrium}

Having derived the solutions to the individual optimization problems of the three sectors in this economy, I am now able to combine these decentralized decisions to define the competitive equilibrium outcome of this economy. Because I have assumed that capital is not used in production, I have abstracted from possible transitional dynamics. Consequently, similar to Romer (1990), the competitive equilibrium defined below constitutes a balanced growth path

\section{Definition 2 Competitive equilibrium}

Given $\mathbf{A}_{0}=\left\{A_{0}, A_{-1}, \ldots\right\}$, and $\left\{k_{0}(h)\right\}_{h=0}^{\bar{h}}$, a competitive equilibrium in this economy is a path

$$
\left\{\left\{c_{t}(h), y_{t}(h), k_{t}(h)\right\}_{h=0}^{1}, \mathbf{P}_{t},\left\{D_{t}(\tau)\right\}_{\tau=0}^{\infty}, X_{R, t}, \Pi_{t}, r_{t}, A_{t}\right\}_{t=1}^{\infty}
$$

such that

(i) Utility maximization: Given $\left\{y_{t}(h), r_{t}, k_{0}(h)\right\}_{t=1}^{\infty},\left\{c_{t}(h)\right\}_{t=1}^{\infty}$ solves the utility maximization problem of the workers of all types $h \in[0,1]$.

(ii) Optimal technology choice: In every period, given $\mathbf{P}_{t}$ and $\mathbf{A}_{t}$, the demand sets $\left\{D_{t}(\tau)\right\}_{\tau=0}^{\infty}$ are determined by the workers' optimal technology choice decision introduced in subsection 3.2.

(iii) Price equilibrium: In every period, given $\mathbf{A}_{t}, \mathbf{P}_{t}$ is the price equilibrium.

(iv) Patent race equilibrium: In every period, the research intensity $X_{R, t}$ solves the patent race equilibrium.

(v) Rents on innovative activity: $\Pi_{t}$ is determined by (10).

(vi) Capital market clearing: In every period, the interest rate $r_{t}$ clears the capital market such that $K_{t}=0$.

(vii) Technological progress: In every period, $A_{t+1}=(1+g) A_{t}$.

In order to derive the competitive equilibrium of this economy it is easiest to rewrite the competitive equilibrium dynamics in terms of transformations of variables that will be constant on the equilibrium path. These transformations turn out to be output, capital, and consumption per efficiency unit, i.e. $Y_{t}^{*}=Y_{t} / A_{t}, K_{t}^{*}=K_{t} / A_{t}$, and $C_{t}^{*}=C_{t} / A_{t}$, prices per efficiency unit, i.e. $\widehat{P}_{t, \tau}$, the interest rate, i.e. $r_{t}$, and the research intensity and income per efficiency unit, i.e. $X_{t, R}^{*}=X_{t, R} / A_{t}$ and $\Pi_{t}^{*}=\Pi_{t} / A_{t}$. In terms of these variables, a competitive equilibrium is defined as a combination of variables

$$
\left\{Y^{*}, K^{*}, C^{*}, \widehat{P}_{\tau}, \Pi^{*}, X_{R}^{*}, r\right\}
$$


such that

$$
\begin{aligned}
Y^{*} & =\widetilde{Y}(g, \mathbf{c}) \\
K^{*} & =0 \\
X_{R}^{*} & =V^{*}(r, \ldots, r ; g, \mathbf{c}) \\
\Pi^{*} & =\sum_{\tau=0}^{M}\left(\frac{1}{1+g}\right)^{\tau} \widetilde{\pi}_{\tau}(g, \mathbf{c})-X_{R}^{*} \\
(1+g) K^{*} & =(1+r) K^{*}+Y^{*}-C^{*}+\Pi^{*} \\
C^{*} / C^{*} & =\left(\frac{1}{1+g}\right)[\beta(1+r)]^{\frac{1}{\sigma}}=1
\end{aligned}
$$

and $\widehat{P}_{\tau}$ is the PSN equilibrium in the machine market. The following proposition establishes its existence and uniqueness.

Proposition 4 Existence and uniqueness of competitive equilibrium For all $g>0, \mathbf{c} \in \mathbb{R}_{+}^{M}$, there exists a unique septuple $\left\{Y^{*}, K^{*}, C^{*}, \widehat{P}_{\tau}, \Pi^{*}, X_{R}^{*}, r\right\}$ that satisfies equations (12) through (17) and where $\widehat{P}_{\tau}$ is the PSN equilibrium.

In the next section, I will show how equipment price indices, as measured by the BEA and BLS, will behave on the competitive equilibrium path of this economy.

\section{Spurious equipment price deflation}

So, what would happen if the BEA and BLS would measure equipment price indices in the economy above? Before I analyze this question in detail, I start off by considering what would be a reasonable price index and productivity index in this economy. In order to consider this, it is important to realize that on the balanced growth path

Implication 1 Average price paid per efficiency unit is constant over time

The total number of efficiency units sold in the market equals

$$
\sum_{\tau=0}^{M} A_{t-\tau} X_{t, \tau}=A_{t} \sum_{\tau=0}^{M}\left(\frac{1}{1+g}\right)^{\tau} \widetilde{X}_{\tau}(g, \mathbf{c})=A_{t} \bar{X}(g, \mathbf{c})
$$


while the total revenue in the market equals

$$
\sum_{\tau=0}^{M} P_{t, \tau} X_{t, \tau}=A_{t} \sum_{\tau=0}^{M}\left(\frac{1}{1+g}\right)^{\tau} \mu_{\tau}(g, \mathbf{c})=A_{t} \bar{P}(g, \mathbf{c})
$$

such that the average price of an efficiency unit equals $\bar{P}(g, \mathbf{c}) / \bar{X}(g, \mathbf{c})$ and is independent of time.

\section{Implication 2 Average production cost per efficiency unit is con- stant over time}

The total production costs of all the efficiency units sold in the market equals

$$
\sum_{\tau=0}^{M} A_{t-\tau} c_{\tau} X_{t, \tau}^{2}=A_{t} \sum_{\tau=0}^{M}\left(\frac{1}{1+g}\right)^{\tau} c_{\tau} \widetilde{X}_{\tau}^{2}(g, \mathbf{c})=A_{t} \bar{C}(g, \mathbf{c})
$$

such that the average production cost per efficiency unit equals $\bar{C}(g, \mathbf{c}) / \bar{X}(g, \mathbf{c})$ and is again independent of time.

These two implications are important because they suggest that $(i)$ because the average production cost per efficiency unit is constant there is no productivity growth in the machine producing sector, (ii) because the average price paid per efficiency unit is constant, any reasonable quality adjusted investment price index should be constant over time.

I will now proceed with the following thought experiment in this section. Suppose that the BEA and BLS would observe the quality of machines, i.e. $A_{t}$, perfectly and would apply their methods to the construction of an investment price index in this economy, how would the resulting investment price index behave? As it turns out, for all the methods used by the BEA and BLS the resulting price index would not be constant, but would instead be steadily declining.

Similar to Section 2, I will again discuss the implications for both matchedmodel as well as hedonic price indices.

\subsection{Matched-model indices}

The application of (3) in my model to construct a matched model price index would yield an estimate of equipment price inflation equal to

$$
\pi_{t}^{M}=\sum_{\tau=1}^{M} \omega_{t, \tau}\left(\frac{P_{t, \tau}}{P_{t-1, \tau-1}}-1\right)
$$




$$
=\sum_{\tau=1}^{M} \omega_{t, \tau}\left(\frac{\mu_{\tau}}{\mu_{\tau-1}}-1\right)<0
$$

which is the theoretical equivalent of (4). Just like I explained in section 2 , equipment price inflation in this model is underestimated due to the continuous erosion of market power of the vintages that are traded, implied by the result that newer vintage have higher markups than older ones such that $\mu_{\tau-1}>\mu_{\tau}$. In fact, the application of matched-model indices in my model economy would lead to the measurement of spurious equipment price deflation.

\subsection{Hedonic price indices}

Hedonic price indices are used by the BEA and BLS to quality adjust the price indices for, among others, computer equipment, and software. They apply two types of hedonic price indices. The first type is based on a sequence of separate cross sectional regressions, each for a specific period. This is the methodology that the BLS applies for the construction of some of its Producer Price Indices. Holdway (2001) contains an excellent explanation of the BLS' methodology. The second type consists of hedonic price indices based on pooled cross-sectional regressions. These are applied by the BEA for the construction of its investment price indices used in the National Income and Product Accounts. Wasshausen (2000) contains a detailed description of the evolution of the hedonic regressions used by the BEA over the years.

In order to address the behavior of these two price indices in my theoretical model, I first describe what the model implies for the cross-sectional behavior of prices. Throughout, I will assume that the quality index $A_{t}$ is observed correctly, which is doubtful in the actual application of hedonic price methods. Prices in my model satisfy

$$
\ln P_{t, \tau}=\ln A_{t-\tau}+\ln \mu_{\tau}
$$

Bearing in mind that (19) is the underlying data generating process, I will again consider the application of log-log hedonic regressions.

A cross-sectional hedonic regression, as used by the BLS, in the context of my theoretical model would be for a specific $t$ and of the form

$$
\ln P_{t, \tau}=\left(\ln \bar{P}_{t}\right)+\beta \ln A_{t-\tau}
$$


the resulting regression coefficient for quality will then equal

$$
\widehat{\beta}=1+\frac{\sum_{\tau=0}^{M-1}\left(\ln A_{t-\tau}-\overline{\ln A_{t-\tau}}\right)\left(\ln \mu_{\tau}-\overline{\ln \mu_{\tau}}\right)}{\sum_{\tau=0}^{M-1}\left(\ln A_{t-\tau}-\overline{\ln A_{t-\tau}}\right)^{2}}>1
$$

where

$$
\overline{\ln A_{t-\tau}}=\frac{1}{M-1} \sum_{\tau=0}^{M-1} \ln A_{t-\tau} \text { and } \overline{\ln \mu_{\tau}}=\frac{1}{M-1} \sum_{\tau=0}^{M-1} \ln \mu_{\tau}
$$

and the summation runs up till $M-1$, because $P_{t, M}=0$ and thus can not be taken a logarithm of. The positive bias in the estimate $\widehat{\beta}$ is an example of the omitted variable problem discussed in section 2 .

How does this positive bias affect measured investment price inflation? To answer this question, I will compare the implication for the sequence of frontier machines over time. The theoretical model implies that $\ln A_{t}=$ $\ln (1+g)+\ln A_{t-1}$ and, as can be seen from (19), $\ln P_{t, 0}=\ln (1+g)+$ $\ln P_{t-1,0}$. Consider a hedonic price index for the frontier machine, which I will denote by $P_{t}^{H}$. The percentage change in the hedonic price index, i.e. $\pi_{t}^{H}$, is equal to the percentage change in the prices minus the part that is attributable to the quality change. That is,

$$
\pi_{t}^{H} \approx \Delta \ln P_{t}^{H}=\Delta \ln P_{t, 0}-\widehat{\beta} \Delta \ln A_{t}=(1-\widehat{\beta}) \ln (1+g)<0
$$

where $\Delta$ is the first difference operator. Hence, the positive bias in the estimate of $\beta$ leads to spurious investment price deflation. The extent of this deflation is increasing in the correlation between $\ln \mu_{\tau}$ and $\ln A_{t-\tau}$. Note that if $\beta=1$ would be estimated correctly, then this method would lead to the proper result that there is no investment price deflation whatsoever. Furthermore, the balanced growth properties of the model imply that $\widehat{\beta}$ and thus $\pi_{t}^{H}$ are independent of time, i.e. $\pi_{t}^{H}=\bar{\pi}^{H}$.

Instead of data on a single cross-section for each year, the BEA pools these cross-sections for the quality adjustment of the price indices used for some types of computer equipment in the NIPA. Wasshausen (2000) contains a detailed description of the hedonic regressions used. In the context of the theoretical model here, the BEA's pooled cross-sectional regressions boil down to the regression of $\ln P_{t, \tau}$ on $\ln A_{t-\tau}$ and time dummies. That is, the regression equation is

$$
\ln P_{t, \tau}=\sum_{t=1}^{T} \delta_{t} D_{t}+\beta \ln A_{t-\tau}
$$


where $D_{t}=1$ in period $t$ and 0 otherwise. It is fairly straightforward to show that, because of the balaced growth properties of the model, in this equation the estimated coefficient on quality, i.e. $\widehat{\beta}$, is the same as in (20). Moreover, the estimated time-varying intercepts, i.e. $\hat{\delta}_{t}$ 's, will satisfy

$$
\hat{\delta}_{t}=\hat{\delta}_{t-1}+(1-\widehat{\beta}) \ln (1+g)
$$

If quality adjusted inflation is directly measured by the changes in the estimated time-varying intercepts, then the estimated equipment price inflation using this method is

$$
\pi_{t}^{H} \approx \hat{\delta}_{t}-\hat{\delta}_{t-1}=(1-\widehat{\beta}) \ln (1+g)<0
$$

which is equal to that measured by the simple cross-sectional method. Again, this method leads to the measurement of spurious equipment price deflation due to imperfect competition.

In the simple theoretical model in this paper, this bias can be eliminated by the inclusion of vintage age dummies. That is, the hedonic regression equation

$$
\ln P_{t, \tau}=\sum_{t=1}^{T} \delta_{t} D_{t}+\sum_{\tau=0}^{M-1} \theta_{\tau} D_{\tau}+\beta_{2} \ln A_{t-\tau}
$$

where $D_{\tau}=1$ if a machine is of vintage age $\tau$ and zero otherwise, would lead to the appropriate regression result that $\hat{\delta}_{t}=\hat{\delta}_{t-1}$ for all $t \geq 1$. Berndt, Griliches and Rapaport (1993) use vintage age dummies in their empirical studies of PC prices and find limited significance. One has to realize, however, that vintage age dummies are a good proxy for the extent of the markup in the theoretical model here, because I have assumed that only one new machine design is invented in each period. Furthermore, the coefficients $\theta_{\tau}$ in (21) are constant because I assume that $g$ is constant over time. Though these two assumptions are innocuous for the expositional purpose of the theoretical model introduced in this paper, they would be unrealistic to make for the purpose of an empirical analysis. For example, in the case of PC's, where Berndt, Griliches, and Rapaport (1993) use dummies for vintage age in years, the frequency of introduction of new models is much higher than once a year.

This is not the first paper to point out that markups might affect hedonic price indices. Pakes (2001), for example, contains an illuminating discussion of the same topic. What is different here is that I show, in the specific theoretical context of my model, that these indices have a bias with a known sign and how this bias comes about through imperfect competition. 
Table 2: Numerical results

\begin{tabular}{ccrrrr}
\hline \hline case & $g$ & $c_{0}$ & \multicolumn{1}{c}{$\gamma$} & \multicolumn{1}{c}{$\bar{\pi}^{M}$} & $\bar{\pi}^{H}$ \\
\hline $\mathrm{A}$ & 0.587 & 0 & 0 & $-67.2 \%$ & $-383.8 \%$ \\
$\mathrm{~B}$ & 0.587 & 30 & 0.125 & $-4.8 \%$ & $-40.3 \%$ \\
$\mathrm{C}$ & 0.587 & 30 & 0.25 & $-7.0 \%$ & $-88.2 \%$ \\
$\mathrm{D}$ & 0.587 & 60 & 0.25 & $-4.5 \%$ & $-59.2 \%$ \\
\hline \hline
\end{tabular}

\subsection{A numerical example}

In the two subsections above, I have shown that the methods applied by the BEA and BLS lead to an upward bias in measured investment price deflation in the theoretical model introduced in this paper. I have, however, not addressed the possible magnitude of this bias. In this subsection, I use a simple numerical example to get at this magnitude.

As one can see from the explanation in the previous subsection, the only parameters that are relevant for this bias are the growth rate of the technological frontier, i.e. $g$, the vintage age dependent cost parameters, collected in the vector $\mathbf{c}$, and the patent length $M$.

As Jaffe (1999) reports, the standard patent length in the U.S. since 1994 is 20 years, so I will fix $M=20$. In order to keep my numerical example in line with my empirical example of section 2, I will choose $g=0.587$. This is the annual growth rate of PC microprocessor speeds implied by Moore's law, i.e. the prediction that the speed of microprocessors will double about once every 18 months.

What is left to choose is the cost structure, c. I will allow for possible learning by doing in the sense that

$$
c_{\tau}=\frac{c_{0}}{(1+\gamma)^{\tau}} \text { where } \gamma \geq 0
$$

Here $\gamma$ reflects the per period percentage gain in efficiency in the production of machines of a particular vintage due to learning by doing. I will illustrate the outcome of the model for different rates of learning by doing and different values of $c_{0}$. The values of $\gamma$ and $c_{0}$ that I use are chosen purely for illustrative purposes to show the effect the cost parameters have on the equilibrium outcome and on the deflation bias.

Table 2 lists the parameter combinations and implied measured investment price inflation rates for matched-model and hedonic price indices. 
For the calculation of the matched model indices I will choose, as Dulberger (1989) suggests, the weights for the matched model price index as the previous period market share of the vintage relative to the other vintages in the index, such that

$$
\omega_{t, \tau}=\frac{\left(\frac{1}{1+g}\right)^{\tau} \mu_{\tau-1}(g, \mathbf{c}) \widetilde{X}_{\tau-1}(g, \mathbf{c})}{\sum_{\tau=1}^{M}\left(\frac{1}{1+g}\right)^{\tau} \mu_{\tau-1}(g, \mathbf{c}) \widetilde{X}_{\tau-1}(g, \mathbf{c})}=\bar{\omega}_{\tau}
$$

and only depends on vintage age and not on time. This implies that $\pi_{t}^{M}=\bar{\pi}^{M}$ is also independent of time.

Before I discuss the estimated deflation rates in detail it is useful to first consider the equilibrium results plotted in Figure 3 . The figure plots the price as a function of the vintage (upper-left), the price per efficiency units as a function of the number of efficiency units (lower-left), the market share for each vintage (upper-right), and the diffusion curve (lower-right). Diffusion is defined as the percentage of people using vintages that are as good as or better than a particular vintage.

In the case of no production costs, i.e. $c_{0}=0$ (case A), the producer of the frontier vintage is the dominating market force. This producer can basically decide what part of the market he conquers and what part he leaves for his competitors. Consequently, the frontier vintage absorbs more than half of the market. If the supplier of the frontier vintage faces significant production costs then decreasing returns to scale might force him to raise his price and to lower his market share in order to cover costs. This effect can be seen because the supplier of the frontier vintage has a lower market share in the case of $\mathrm{D}$ than in C. Learning by doing gives the suppliers of older vintages a relative competitive edge over those of new vintages. Consequently, an increase in the learning by doing rate shifts market share from newer to older vintages. This can be seen when one compares the market share curves for cases B and $\mathrm{C}$, where the increased learning by doing increases the market shares of vintages 6 through 18 at the expense of the other ones. The lower-left hand panel of Figure 3 plots $\mu_{\tau}(g, \mathbf{c})$. As you can see, $\mu_{\tau}(g, \mathbf{c})$ is relatively flat for the cases $\mathrm{B}, \mathrm{C}$, and $\mathrm{D}$ and has a lower correlation with $A_{t-\tau}$ plotted on the $x$-axis of that panel. Consequently, the downward bias in the hedonic price index is much smaller in cases B-D, as is listed in Table 2, than in case A. In fact, in case A the bias in the estimated coefficient in the hedonic regression is so severe that it implies an infeasible equipment deflation rate of $-383 \%$. 

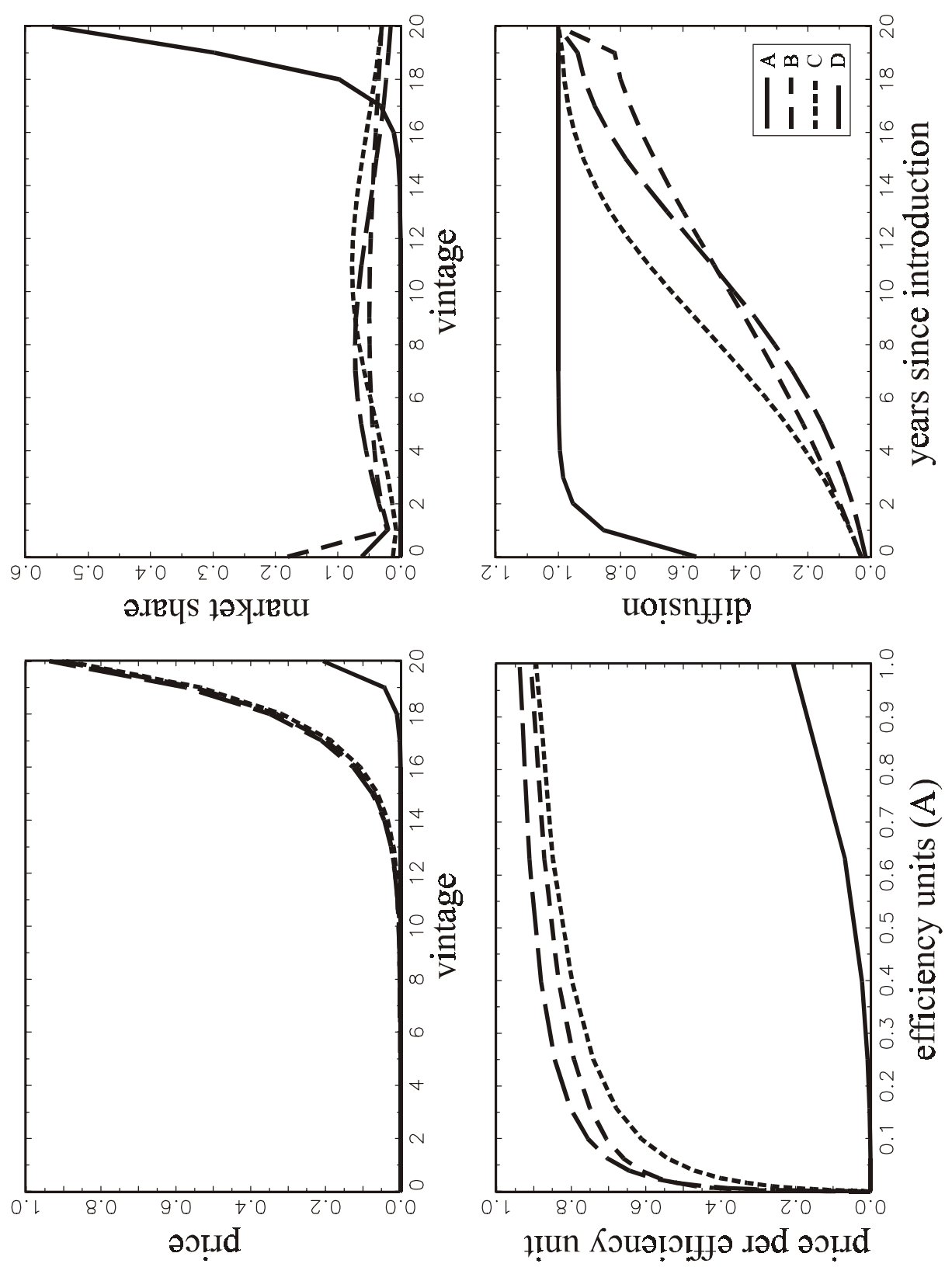

Figure 3: Equilibrium outcome for Moore's law $(g=0.587)$ 
The conclusion of this numerical exercise is thus that in my theoretical model the potential biases in measured investment price deflation can be quite large. For hedonic price indices they can even be so large that they lead to infeasible deflation rates. Furthermore, these biases turn out to be very sensitive to the underlying market structure.

\section{Conclusion}

In this paper I argued that, by not taking into account the fact that equipment markets are not perfectly competitive, the BEA and BLS are likely to overestimate investment price deflation. The main intuition behind this result is that what their price indices might capture is actually not a price decrease but the constant erosion of the market power of existing vintages of machines in the market. To illustrate my argument, I introduced an endogenous growth model in which suppliers of different vintages of machines imperfectly compete for the demand of a heterogeneous set of workers. This market structure results in a price schedule which would lead the BLS and BEA to find investment price deflation, even though the model economy does not exhibit any investment price deflation at all. The measured deflation in the model economy is a complete statistical artifact.

The theoretical example given in this paper is an extreme case. In practice there is good reason to believe that the quality of investment goods has been steadily improving. Quality adjustments of capital goods, however, are currently treated with double standards. On the one hand, there are computer equipment and software to which the BEA and BLS extensively apply the quality adjustment methods discussed in this paper. While on the other hand, there are the other capital goods for which there is no serious effort to quality adjust.

This paper suggests that real investment in computer equipment and software is likely to be overstated because of the bias discussed here. Thus, everything else equal, the results in this paper suggest an overestimation of real output growth and productivity growth in the IT producing sector. However, real output growth and productivity for other capital goods producing sectors is likely to be underestimated because it is virtually not quality adjusted at all.

In this paper, I have focussed my attention on equipment price indices, the bias that I discuss, however, is a potential problem for any product market 
with rapid technological change to which matched model and hedonic price indices are applied. 


\section{References}

[1] Aghion, Phillipe, and Peter Howitt (1992), "A Model of Growth Through Creative Destruction", Econometrica, 60, 323-351.

[2] Aizcorbe, Ana, Carol Corrado, and Mark Doms (2000), "Constructing Price and Quantity Indexes for High Technology Goods", mimeo, Federal Reserve Board of Governors.

[3] Berndt, Ernst, Zvi Griliches, and Neal Rapaport (1993), "Econometric Estimates of Prices Indexes for Personal Computers in the 1990s", working paper \#4549, NBER.

[4] Caselli, Francesco and Jaume Ventura (2000), "A Representative Consumer Theory of Distribution", American Economic Review, 90, 909926.

[5] Chari, V.V., and Hugo Hopenhayn (1991), "Vintage Human Capital, Growth, and the Diffusion of New Technology", Journal of Political Economy, 99, 1142-1165.

[6] Cockburn, Iain and Aslam Anis (1998), "Hedonic Analysis of Arthritis Drugs", working paper \#65\%4, NBER.

[7] Dulberger, Ellen (1989), "The Application of an Hedonic Model to a Quality Adjusted Price Index for Computer Processors", in Technology and Capital Formation, Dale Jorgenson and Ralph Landau, eds.. Cambridge: MIT Press.

[8] Gilbert, Richard and David Newbery (1982), "Preemptive Patenting and the Persistence of Monopoly", American Economic Review, 72, 514-526.

[9] Greenwood, Jeremy, Zvi Hercowitz and Per Krusell (1997), "Long-Run Implications of Investment-Specific Technological Change", American Economic Review, 87, 342-362.

[10] Gordon, Robert (2000), "Does the 'New Economy' Measure Up to the Great Inventions of the Past?", working paper \#7833, NBER.

[11] Grossman, Gene and Elhanan Helpman (1991), Innovation and Growth in the Global Economy, Cambridge: MIT Press. 
[12] Hall, Robert (1988), "The Relation between Price and Marginal Cost in U.S. Industry", Journal of Political Economy, 96, 921-947.

[13] Holdway, Michael (2001), "Quality Adjusting Computer Prices in the Producer Price Index: An Overview", mimeo, Bureau of Labor Statistics. (www.bls.gov/ppicomqa.htm)

[14] Irwin, Douglas and Peter Klenow (1994), "Learning-by-Doing Spillovers in the Semiconductor Industry", Journal of Political Economy, 102, $1200-1227$.

[15] Jaffe, Adam (1999), "The U.S. Patent System in Transition: Policy Innovation and Innovation Process", working paper \#7280, NBER.

[16] Jorgenson, Dale, and Kevin Stiroh (2000), "Raising the Speed Limit: U.S. Economic Growth in the Information Age", Brookings Papers on Economic Activity 1, 2000, 125-211.

[17] Jovanovic, Boyan (1999), "Vintage Capital and Inequality", Review of Economic Dynamics, 1, 497-530.

[18] Oliner, Stephen, and Daniel Sichel (2000), "The Resurgence of Growth in the Late 1990s: Is Information Technology the Story?", Finance and Economics Discussion Series \#2000-20, Federal Reserve Board of Governors.

[19] Pakes, Ariel (2001), "Some Notes on Hedonic Price Indices, With an Application to PC's", mimeo, Harvard.

[20] Reinganum, Jennifer (1983), "Uncertain Innovation and the Persistence of Monopoly", American Economic Review, 73, 741-783.

[21] Romer, Paul (1990), "Endogenous Technological Change", Journal of Political Economy, 98, S71-S102.

[22] Sattinger, Michael (1975), "Comparative Advantage and the Distributions of Earnings and Abilities", Econometrica, 43, 455-468.

[23] Violante, Giovanni, Lee Ohanian, José-Victor Ríos-Rull, and Per Krusell (2000), "Capital-skill Complementarities and Inequality: A Macroeconomic Analysis", Econometrica, 1029-1053. 
[24] Wasshausen, Dave (2000), "Computer Prices in the National Accounts", mimeo, Bureau of Economic Analysis.

[25] Woodford, Michael and Julio Rotemberg (1999), "The Cyclical Behavior of Prices and Costs", in John Taylor and Michael Woodford, eds., Handbook of Macroeconomics, vol. 1B. 


\section{Proofs}

\section{Proof of proposition 1: Properties of demand sets}

(i) Consider $h^{\prime}>h$ and $\tau^{\prime}>\tau$, then $h \in D_{t}(\tau)$ implies that

$$
\forall s \in \mathbb{N}: A_{t-\tau} h-P_{t, \tau} \geq A_{t-s} h-P_{t, s}
$$

or, equivalently, in terms of marginal benefits and costs

$$
\forall s \in \mathbb{N}:\left(A_{t-\tau}-A_{t-s}\right) h \geq P_{t, \tau}-P_{t, s}
$$

Consequently, because for all $\tau^{\prime}>\tau$ strictly positive technological progress implies $A_{t-\tau^{\prime}}>$ $A_{t-\tau}$, the marginal benefits from updating for the worker of type $h^{\prime}$ exceed those of the worker of type $h$. That is,

$$
\forall \tau^{\prime}>\tau:\left(A_{t-\tau}-A_{t-\tau^{\prime}}\right) h \geq P_{t, \tau}-P_{t, \tau^{\prime}}
$$

This implies that it must thus be true that $h^{\prime} \notin D_{t}\left(\tau^{\prime}\right)$ for all $\tau^{\prime}>\tau$.

(ii) Because patents expire after $M$ periods, all intermediate goods producers of vintages of age $M$ or older face perfect competition. As a result, the price of these vintages is competed down to zero. Consequently all workers will use at least the best technology that is available for free, such that no one will use a technology that is older than $M$.

(iii) Since $h \backsim$ unif $(0,1)$, it suffices to prove that $\widetilde{\mathcal{H}}$ contains a finite number of elements. Since workers will use only technologies $\{0, \ldots, M\}$ there are only a finite number of combinations between which workers can be indifferent. I will show that, if a worker of type $h$ is indifferent between two intermediate goods, then no other worker will be. That is, define the set

$$
\widehat{\mathcal{H}}_{t}\left(\tau, \tau^{\prime}\right)=\left\{h \in[0,1] \mid h \in D_{t}(\tau) \wedge h \in D_{t}\left(\tau^{\prime}\right)\right\}
$$

such that

$$
\widetilde{\mathcal{H}}_{t}=\bigcup_{\tau=0}^{M-1} \bigcup_{\tau^{\prime}=\tau+1}^{M} \widehat{\mathcal{H}}_{t}\left(\tau, \tau^{\prime}\right)
$$

and, denoting the Lebesque measure as $\mu($.$) , we obtain$

$$
\mu\left(\widetilde{\mathcal{H}}_{t}\right) \leq \frac{1}{\bar{h}} \sum_{\tau=0}^{M-1} \sum_{\tau^{\prime}=\tau+1}^{M} \mu\left(\widehat{\mathcal{H}}_{t}\left(\tau, \tau^{\prime}\right)\right)
$$

I will simply show that $\forall \tau^{\prime}>\tau: \mu\left(\widehat{\mathcal{H}}_{t}\left(\tau, \tau^{\prime}\right)\right)=0$. Let $h \in[0,1]$ be such that $h \in D_{t}(\tau)$ as well as $h \in D_{t}\left(\tau^{\prime}\right)$ for $\tau^{\prime}>\tau$. In that case

$$
A_{t-\tau} h-P_{t, \tau}=A_{t-\tau^{\prime}} h-P_{t, \tau^{\prime}}
$$

or equivalently

$$
\left(A_{t-\tau}-A_{t-\tau^{\prime}}\right) h=P_{t, \tau}-P_{t, \tau^{\prime}}
$$


This, however implies that for all $h^{\prime}>h>h^{\prime \prime}$

$$
\left(A_{t-\tau}-A_{t-\tau^{\prime}}\right) h^{\prime}>P_{t, \tau}-P_{t, \tau^{\prime}}>\left(A_{t-\tau}-A_{t-\tau^{\prime}}\right) h^{\prime \prime}
$$

such that the workers of type $h^{\prime}>h$ will prefer $\tau$ over $\tau^{\prime}$, while workers of type $h^{\prime \prime}<h$ will do the opposite. Hence, $\widehat{\mathcal{H}}_{t}\left(\tau, \tau^{\prime}\right)=\{h\}$ and is of measure zero.

(iv) Consider $h^{\prime \prime}>h^{\prime}>h$ such that $h^{\prime \prime} \in D_{t}(\tau)$ as well as $h \in D_{t}(\tau)$. This implies that

$$
\forall s \in \mathbb{N}:\left(A_{t-\tau}-A_{t-s}\right) h^{\prime \prime}>\left(A_{t-\tau}-A_{t-s}\right) h^{\prime}>\left(A_{t-\tau}-A_{t-s}\right) h \geq P_{t, \tau}-P_{t, s}
$$

such that

$$
\forall s \in \mathbb{N}: A_{t-\tau} h^{\prime}-P_{t, \tau}>A_{t-s} h^{\prime}-P_{t, s}
$$

and thus $h^{\prime} \in D_{t}(\tau)$. Hence, $D_{t}(\tau)$ is connected.

\section{Proof of proposition 2: Solution to equilibrium price schedule}

I will prove this proposition in two parts. The first consists of my proof of $(i)$ and $(i i)$. In the second part, I use $(i)$ and $(i i)$, together with results $(i)$ and $(i v)$ of proposition 1 to prove $(i i i)$.

Proof of (i) and (ii): I will prove these parts by induction. The proof applies lemmas 5 and 6 . Lemma 5 implies that, no matter what the other machine producers do, the frontier machine producer will always set a price $P_{t, 0}>\frac{c_{0}}{2} A_{t} X_{t, 0}$ and make strictly positive profits. This lemma initializes the induction. Lemma 6 then shows that, independently of what the suppliers of older vintages do, if all suppliers of newer vintages charge a markup and make strictly positive profits, then so will the supplier of vintage $\tau \in\{1, \ldots, M-1\}$. Combining these two lemmas implies that, if there is a Pure Strategy Nash equilibrium, then it must be one in which $(i)$ all monopoly suppliers of machines charge a strictly positive markup and make strictly positive profits. That is,

(i) $P_{t, \tau}>\frac{c_{\tau}}{2} A_{t-\tau} X_{t, \tau}$ for all $\tau \in\{0, \ldots, M-1\}$ and (ii) $\mu(D(\tau))>0$ for all $\tau \in\{0, \ldots, M\}$

Combining (ii) with parts $(i)$ and $(i v)$ of proposition 1, this implies that if there is a Pure Strategy Nash equilibrium, then there exist $\left\{h_{t}(0), \ldots, h_{t}(M-1)\right\}$ such that

$$
D(\tau)=\left\{\begin{array}{ccc}
{\left[h_{t}(0), \bar{h}\right]} & \text { for } & \tau=0 \\
{\left[h_{t}(\tau), h_{t}(\tau-1)\right]} & \text { for } & \tau \in\{1, \ldots, M-1\} \\
{\left[0, h_{t}(M-1)\right]} & \text { for } & \tau=M
\end{array}\right.
$$

and

$$
h_{t}(\tau)=\frac{A_{t-\tau}}{A_{t-\tau}-A_{t-\tau-1}} \hat{P}_{t, \tau}-\frac{A_{t-\tau-1}}{A_{t-\tau}-A_{t-\tau-1}} \hat{P}_{t, \tau+1}
$$

which is the basis for the derivation of the form of the Pure Strategy Nash equilibrium in part (iii).

Proof of (iii), (iv), and (v): A machine producer of machines of vintage age $\tau$ chooses $\hat{P}_{t, \tau}$ to maximize profits

$$
\pi_{t, \tau}=A_{t-\tau}\left(\hat{P}_{t, \tau}-\frac{c_{\tau}}{2} X_{t, \tau}\right) X_{t, \tau}
$$


since parts $(i)$ and (ii) have proven that the solution to the PSN-equilibrium is interior, I will simply use standard calculus to find a profit maximizing solution. The associated first order necessary condition for the profit maximization problem is

$$
0=A_{t-\tau}\left[\hat{P}_{t, \tau} \frac{\partial X_{t, \tau}}{\partial \hat{P}_{t, \tau}}+X_{t, \tau}-c_{\tau} X_{t, \tau} \frac{\partial X_{t, \tau}}{\partial \hat{P}_{t, \tau}}\right]
$$

such that if there is an interior solution to this problem, it must satisfy

$$
\hat{P}_{t, \tau}=\left[c_{\tau}-\frac{1}{\partial X_{t, \tau} / \partial \hat{P}_{t, \tau}}\right] X_{t, \tau}
$$

For the supplier of a non-frontier vintage, i.e. $\tau \in\{1, \ldots, M-1\}$, the demand set satisfies

$$
\begin{aligned}
X_{t, \tau} & =\left[\frac{A_{t-\tau+1}}{A_{t-\tau+1}-A_{t-\tau}} \hat{P}_{t, \tau-1}-\frac{A_{t-\tau}}{A_{t-\tau+1}-A_{t-\tau}} \hat{P}_{t, \tau}-\frac{A_{t-\tau}}{A_{t-\tau}-A_{t-\tau-1}} \hat{P}_{t, \tau}+\frac{A_{t-\tau-1}}{A_{t-\tau}-A_{t-\tau-1}} \hat{P}_{t, \tau+1}\right] \\
& =w_{t, \tau}^{\tau-1} \hat{P}_{t, \tau-1}-\left(w_{t, \tau}^{\tau-1}+w_{t, \tau}^{\tau+1}\right) \hat{P}_{t, \tau}+w_{t, \tau}^{\tau+1} \hat{P}_{t, \tau+1}
\end{aligned}
$$

such that

$$
\frac{\partial X_{t, \tau}}{\partial \hat{P}_{t, \tau}}=-\left(w_{t, \tau}^{\tau-1}+w_{t, \tau}^{\tau+1}\right)
$$

Using the above two equations to solve the first order necessary condition yields

$$
\hat{P}_{t, \tau}=\left[\frac{1+c_{\tau}\left(w_{t, \tau}^{\tau+1}+w_{t, \tau}^{\tau-1}\right)}{2+c_{\tau}\left(w_{t, \tau}^{\tau+1}+w_{t, \tau}^{\tau-1}\right)}\right]\left[\frac{w_{t, \tau}^{\tau-1}}{w_{t, \tau}^{\tau+1}+w_{t, \tau}^{\tau-1}} \widehat{P}_{t, \tau-1}+\frac{w_{t, \tau}^{\tau-1}}{w_{t, \tau}^{\tau+1}+w_{t, \tau}^{\tau-1}} \widehat{P}_{t, \tau+1}\right]
$$

which is the first part of the second order difference equation in the proposition. Substituting this expression in that for the demand set yields that

$$
X_{t, \tau}=\frac{w_{t, \tau}^{\tau+1}+w_{t, \tau}^{\tau-1}}{1+c_{\tau}\left(w_{t, \tau}^{\tau+1}+w_{t, \tau}^{\tau-1}\right)} \hat{P}_{t, \tau}
$$

For the supplier of the frontier vintage, the demand set satisfies

$$
X_{t, 0}=\left[1-\left(1+w_{t, 0}^{1}\right) \hat{P}_{t, 0}+w_{t, 0}^{1} \hat{P}_{t, 1}\right]
$$

such that

$$
\frac{\partial X_{t, 0}}{\partial \hat{P}_{t, 0}}=-\left(1+w_{t, 0}^{1}\right)
$$

Using the above two equations to solve the necessary condition for an interior solution yields

$$
\widehat{P}_{t, 0}=\left[\frac{1+c_{0}\left(1+w_{t, 0}^{1}\right)}{2+c_{0}\left(1+w_{t, 0}^{1}\right)}\right]\left[\frac{1}{1+w_{t, 0}^{1}}+\frac{w_{t, 0}^{1}}{1+w_{t, 0}^{1}} \widehat{P}_{t, 1}\right]
$$


Substituting this into the expression for the demand set gives

$$
X_{t, 0}=\frac{1+w_{t, 0}^{1}}{1+c_{0}\left(1+w_{t, 0}^{1}\right)} \hat{P}_{t, 0}
$$

What is left to show is that $\hat{P}_{t, \tau}>\hat{P}_{t, \tau+1}$. This follows from the fact that for $\tau \in$ $\{0, \ldots, M-1\}$, the second order difference equation that has to be satisfied in equilibrium implies

$\hat{P}_{t, \tau}=\left[1+c_{\tau}\left(w_{t, \tau}^{\tau+1}+w_{t, \tau}^{\tau-1}\right)\right]\left[\frac{w_{t, \tau}^{\tau-1}}{w_{t, \tau}^{\tau+1}+w_{t, \tau}^{\tau-1}}\left(\widehat{P}_{t, \tau-1}-\widehat{P}_{t, \tau}\right)-\frac{w_{t, \tau}^{\tau-1}}{w_{t, \tau}^{\tau+1}+w_{t, \tau}^{\tau-1}}\left(\widehat{P}_{t, \tau}-\widehat{P}_{t, \tau+1}\right)\right]>0$

Since $\left(\widehat{P}_{t, M-1}-\widehat{P}_{t, M}\right)>0$, a simple induction argument can be used to show that $\widehat{P}_{t, \tau}-$ $\widehat{P}_{t, \tau+1}>0$ for all $\tau \in\{0, \ldots, M-1\}$.

\section{Proof of proposition 3: Value of innovation, output, etc., at con- stant $g$}

(i) Note that, if $g$ is constant, the recursion (9) can be written as a set of linear equations. In matrix form, with the appropriately defined matrices

$$
\underset{M+1 \times M+1}{\mathbf{F}(g, \mathbf{c})} \widehat{\mathbf{P}}_{t}=\underset{M+1 \times 1}{\mathbf{G}(g, \mathbf{c})}
$$

such that the equilibrium vector with prices equals

$$
\widehat{\mathbf{P}}_{t}=\left[[\mathbf{F}(g, \mathbf{c})]^{-1} \mathbf{G}(g, \mathbf{c})\right]
$$

which implies that we can write $\widehat{P}_{t, \tau}=\mu_{\tau}(g, \mathbf{c})$ where $\mu_{\tau}(g, \mathbf{c})>\mu_{\tau+1}(g, \mathbf{c})$ simply because $\hat{P}_{t, \tau}$ is decreasing in $\tau$.

(ii) For the demand sets we obtain that we can write

$$
X_{t, \tau}=\left\{\begin{array}{lll}
\frac{1+w_{t, 0}^{1}}{1+c_{0}\left(1+w_{t, 0}^{1}\right)} \mu_{0}(g, \mathbf{c}) & \text { for } \quad \tau=0 \\
\frac{w_{t, \tau}^{\tau+1}+w_{t, \tau}^{\tau-1}}{1+c_{\tau}\left(w_{t, \tau}^{\tau+1}+w_{t, \tau}^{\tau-1}\right)} \mu_{\tau}(g, \mathbf{c}) & \text { for } \quad \tau=1, \ldots, M-1 \\
1-\sum_{\tau=0}^{M-1} X_{t, \tau} & \text { for } \quad \tau=M
\end{array}\right.
$$

However, since when $g$ is constant $w_{t, \tau}^{\tau+1}$ and $w_{t, \tau}^{\tau-1}$ only depend on $g$ and not on $t$ for all $\tau=1, \ldots, M-1$, we can write $X_{t, \tau}=\tilde{X}_{\tau}(g, \mathbf{c})$ for $\tau=1, \ldots, M-1$. In that case however, $X_{t, M}=1-\sum_{\tau=0}^{M-1} \tilde{X}_{\tau}(g, \mathbf{c})=\tilde{X}_{M}(g, \mathbf{c})$ and is also constant over time.

(iii) Aggregate output in terms of efficiency units can be written as

$$
\begin{aligned}
Y_{t}^{*} & =\frac{Y_{t}}{A_{t}}=\frac{1}{A_{t}} \sum_{\tau=0}^{M} \int_{h \in D_{t}(\tau)}\left[A_{t-\tau} h-P_{t, \tau}\right] d h \\
& =\frac{1}{A_{t}} \sum_{\tau=0}^{M} A_{t-\tau} \underbrace{\int_{h \in D_{t}(\tau)} h d h}_{Z_{t, \tau}}-P_{t, \tau} X_{t, \tau}
\end{aligned}
$$


Note that

$$
\frac{1}{\bar{h}} \int_{a}^{b} h d h=\frac{1}{2 \bar{h}}\left(a^{2}-b^{2}\right)=\frac{1}{2}\left[\frac{1}{\bar{h}}(a-b)\right](a+b)
$$

Applying this to the equation for aggregate yields

$$
\begin{aligned}
Z_{t, \tau} & =\left\{\begin{array}{clc}
\frac{1}{2} X_{t, \tau}\left[1+h_{t}(0)\right] & \text { for } & \tau=0 \\
\frac{1}{2} X_{t, \tau}\left[h_{t}(\tau-1)+h_{t}(\tau)\right] & \text { for } & \tau=1, \ldots, M-1 \\
\frac{1}{2} X_{t, \tau}\left[h_{t}(M-1)\right] & \text { for } & \tau=M
\end{array}\right. \\
& =X_{t, \tau} Z_{t, \tau}^{*}
\end{aligned}
$$

Using this notation, aggregate output has the representation

$$
Y_{t}^{*}=\frac{1}{A_{t}} \sum_{\tau=0}^{M} X_{t, \tau}\left[A_{t-\tau} Z_{t, \tau}^{*}-P_{t, \tau}\right]
$$

where

$$
Z_{t, \tau}^{*}=\left\{\begin{array}{ccc}
\frac{1}{2}\left[1+\left(1+w_{t, 0}^{1}\right) \hat{P}_{t, 0}-w_{t, 0}^{1} \hat{P}_{t, 1}\right] & \text { for } & \tau=0 \\
\frac{1}{2}\left[w_{t, \tau}^{\tau-1} \hat{P}_{t, \tau-1}-\left(2+w_{t, \tau}^{\tau-1}+w_{t, \tau}^{\tau+1}\right) \hat{P}_{t, \tau}-w_{t, \tau}^{\tau+1} \hat{P}_{t, \tau+1}\right] & \text { for } & \tau=1, \ldots, M-1 \\
\frac{1}{2} w_{t, M}^{M-1} \hat{P}_{t, \tau-1} & \text { for } & \tau=M
\end{array}\right.
$$

Since again $w_{t, \tau}^{\tau+1}$ and $w_{t, \tau}^{\tau-1}$ only depend on $g$ and not on $t$ and $\hat{P}_{t, \tau}=\mu_{\tau}(g, \mathbf{c})$, we can write $Z_{t, \tau}^{*}=\tilde{z}_{\tau}(g, \mathbf{c})$. This means that output can be represented as

$$
\begin{aligned}
Y_{t}^{*} & =\frac{1}{A_{t}} \sum_{\tau=0}^{M} \tilde{X}_{\tau}(g, \mathbf{c})\left[A_{t-\tau} \tilde{z}_{\tau}(g, \mathbf{c})-\mu_{\tau}(g, \mathbf{c})\right] \\
& =\sum_{\tau=0}^{M} \tilde{X}_{\tau}(g, \mathbf{c})\left[\left(\frac{1}{1+g}\right)^{\tau} \tilde{z}_{\tau}(g, \mathbf{c})-\mu_{\tau}(g, \mathbf{c})\right] \\
& =\tilde{Y}(g, \mathbf{c})
\end{aligned}
$$

(iv) For the profits we obtain that

$$
\begin{aligned}
\pi_{t, \tau}^{*} & =\frac{\pi_{t, \tau}}{A_{t-\tau}}=\left(\hat{P}_{t, \tau}-\frac{c_{\tau}}{2} X_{t, \tau}\right) X_{t, \tau} \\
& =\left(p_{\tau}(g, \mathbf{c})-\frac{c_{\tau}}{2} \tilde{X}_{\tau}(g, \mathbf{c})\right) \tilde{X}_{\tau}(g, \mathbf{c}) \\
& =\tilde{\pi}_{\tau}(g, \mathbf{c})
\end{aligned}
$$

(v) and (vi) Follow directly from the explanation in the main text.

Proof of proposition 4: Existence and uniqueness of competitive equilibrium 
The competitive equilibrium equations (12) through (17) can be solved sequentially. That is, (17) pins down the equilibrium interest rate as

$$
r=\frac{1}{\beta}(1+g)^{\sigma}-1>0
$$

At this constant interest rate the value of a new innovation equals

$$
V^{*}(r, \ldots, r ; g, \mathbf{c})=\left(\frac{1}{1+r}\right) \sum_{s=0}^{M-1}\left(\frac{1}{1+g}\right)^{s}\left(\frac{1}{1+r}\right)^{s} \tilde{\pi}_{s}(g, \mathbf{c})=X_{R}^{*}
$$

and the profits from the innovative activities equal

$$
\Pi^{*}=\sum_{s=0}^{M-1}\left(\frac{1}{1+g}\right)^{s}\left[1-\left(\frac{1}{1+r}\right)^{s+1}\right] \tilde{\pi}_{s}(g, \mathbf{c})>0
$$

From proposition 3 we know that for any $g>0, Y^{*}=\tilde{Y}(g, \mathbf{c})>0$ is unique, which yields that steady state consumption equals

$$
C^{*}=Y^{*}+\Pi^{*}>0
$$

Hence a competitive equilibrium path exists and is unique.

Lemma 5 Independent of $\mathbf{P}_{t, 0}^{\prime}$, the supplier of the frontier vintage will choose $P_{t, 0}>$ $\frac{c_{0}}{2} A_{t} \mu\left(D_{t}(0)\right)$.

Proof: In order to prove this and the following lemma, it is easiest to consider

$$
z_{\tau}(h)=\max _{s \in\{0, \ldots, M\} \backslash T}\left(A_{t-s} h-P_{t, s}\right)
$$

and

$$
\bar{z}_{\tau}(h)=\max _{s<T}\left(A_{t-s} h-P_{t, s}\right), \underline{z}_{\tau}(h)=\max _{s>T}\left(A_{t-s} h-P_{t, s}\right), \text { and } W_{\tau}(h)=A_{t-\tau} h-P_{t, \tau}
$$

then

$$
D_{t}(\tau)=\left\{h \in[0,1] \mid W_{\tau}(h) \geq z_{\tau}(h)\right\}
$$

The properties of $\bar{z}_{\tau}(h)$ and $\underline{z}_{\tau}(h)$, which I will not prove here in detail, are $(i) \bar{z}_{\tau}(h)$ and $\underline{z}_{\tau}(h)$ are continuous on $[0,1],(i i) \underline{z}_{\tau}(0)=0,(i i i)$ if $P_{t, s}>0$ for all $s>\tau$, then $\bar{z}_{\tau}(0)<0$, and $\left(\right.$ iii) let $h^{\prime}>h$, then

$$
\bar{z}_{\tau}\left(h^{\prime}\right)-\bar{z}_{\tau}(h) \geq A_{t-(\tau-1)}\left(h^{\prime}-h\right) \text { and } \underline{z}_{\tau}\left(h^{\prime}\right)-\underline{z}_{\tau}(h) \leq A_{t-(\tau+1)}\left(h^{\prime}-h\right)
$$

For the frontier vintage, let the producer choose $h^{\prime}=1-\varepsilon$ such that all workers of type $h^{\prime}$ and higher will choose the frontier vintage. Independent of $\mathbf{P}_{t, 0}^{\prime}$, this can be done by choosing

$$
P_{t, 0} \geq\left[A_{t}-A_{t-1}\right] h^{\prime}=\left[A_{t}-A_{t-1}\right](1-\varepsilon)>0
$$


In that case demand for the frontier vintage equals $\mu\left(D_{t}(\tau)\right)=\varepsilon$, while profits equal

$$
\begin{aligned}
\pi_{t, 0} & =P_{t, 0} \varepsilon-\frac{c_{0}}{2} A_{t} \varepsilon^{2} \\
& \geq\left[\left[A_{t}-A_{t-1}\right](1-\varepsilon)-\frac{c_{0}}{2} A_{t} \varepsilon\right] \varepsilon \\
& =\left[\left[A_{t}-A_{t-1}\right]-\left[\left(1+\frac{c_{0}}{2}\right) A_{t}-A_{t-1}\right] \varepsilon\right] \varepsilon
\end{aligned}
$$

such that the producer of the frontier vintage makes strictly positive profits, i.e. $\pi_{t, 0}>0$, whenever it chooses

$$
0<\varepsilon<\left[A_{t}-A_{t-1}\right] /\left[\left(1+\frac{c_{0}}{2}\right) A_{t}-A_{t-1}\right]
$$

which is always feasible

Lemma 6 If $P_{t, s}>0$ for all $s<\tau$, then, independent of $P_{t, \tau+1}, \ldots, P_{t, M}$, the supplier of the vintage of age $\tau$ will choose $P_{t, \tau}>\frac{c_{\tau}}{2} A_{t-\tau} \mu\left(D_{t}(\tau)\right)$.

Proof:If $P_{t, s}>0$, then we know that $\bar{z}_{\tau}(0)<0$, and we can distinguish two cases: (i) $\bar{z}_{\tau}(1) \leq \underline{z}_{\tau}(1)$ : in that case the suppliers of the more recent vintages than that of age $\tau$ have chosen their prices so high that they are being competed out of the market by suppliers of vintages older than $\tau$. In this case the vintage of age $\tau$ is essentially in the same situation as the supplier of the frontier vintage in Lemma 5 and the proof of can be applied Lemma 5 again.

(ii) $\bar{z}_{\tau}(1)>\underline{z}_{\tau}(1)$ : Because $\bar{z}_{\tau}(0)<0=\underline{z}_{\tau}(0)$ and both $\bar{z}_{\tau}(h)$ and $\underline{z}_{\tau}(h)$ are continuous, we know that in this case there must exist an $h^{\prime} \in(0,1)$ such that $\bar{z}_{\tau}\left(h^{\prime}\right)=\underline{z}_{\tau}\left(h^{\prime}\right)$. Hence, by choosing $P_{t, \tau}=A_{t-\tau} h^{\prime}-\bar{z}_{\tau}\left(h^{\prime}\right)$, the worker would be indifferent between at least three vintages of machine and would obtain an income level of $\bar{z}_{\tau}\left(h^{\prime}\right)=\underline{z}_{\tau}\left(h^{\prime}\right)$. If a worker of type $h<h^{\prime}$ would use the machine of age $\tau$, then he would obtain

$$
A_{t-\tau} h-P_{t, \tau}=\underline{z}_{\tau}\left(h^{\prime}\right)-A_{t-\tau}\left(h-h^{\prime}\right)<\underline{z}_{\tau}\left(h^{\prime}\right)
$$

and if a worker of type $h>h^{\prime}$ would the machine of age $\tau$, then he would obtain

$$
A_{t-\tau} h-P_{t, \tau}=\bar{z}_{\tau}\left(h^{\prime}\right)+A_{t-\tau}\left(h-h^{\prime}\right)<\bar{z}_{\tau}\left(h^{\prime}\right)
$$

Hence, the choice of $P_{t, \tau}=A_{t-\tau} h^{\prime}-\bar{z}_{\tau}\left(h^{\prime}\right)$ is the knife-edge case in which the demand set for vintage $\tau$ is a singleton. Now, if the supplier of vintage $\tau$ chooses

$$
P_{t, \tau}=A_{t-\tau} h^{\prime}-\bar{z}_{\tau}\left(h^{\prime}\right)-\delta
$$

then it can be easily shown that

$$
0<\mu\left(D_{t}(\tau)\right) \leq \delta\left(\frac{1}{A_{t-\tau}-A_{t-\tau-1}}-\frac{1}{A_{t-\tau+1}-A_{t-\tau}}\right)
$$

and that the resulting profits satisfy

$$
\pi_{t, \tau}=\left[\left\{A_{t-\tau} h^{\prime}-\bar{z}_{\tau}\left(h^{\prime}\right)\right\}-\delta\left[1+\frac{1}{2} \frac{c_{\tau} A_{t-\tau}}{A_{t-\tau}-A_{t-\tau-1}}+\frac{1}{2} \frac{c_{\tau} A_{t-\tau}}{A_{t-\tau+1}-A_{t-\tau}}\right]\right] \mu\left(D_{t}(\tau)\right)
$$


Hence, $\pi_{t, \tau}$ is strictly positive whenever

$$
0<\delta<\left\{A_{t-\tau} h^{\prime}-\bar{z}_{\tau}\left(h^{\prime}\right)\right\} /\left[1+\frac{1}{2} \frac{c_{\tau} A_{t-\tau}}{A_{t-\tau}-A_{t-\tau-1}}+\frac{1}{2} \frac{c_{\tau} A_{t-\tau}}{A_{t-\tau+1}-A_{t-\tau}}\right]
$$

which again is a feasible choice independent of the prices chosen by the suppliers of vintages older than age $\tau$

\section{Data}

This appendix contains the data on microprocessor prices that I used in my empirical examples. They are taken from two sources ${ }^{8}$ and cover prices for Intel's Pentium 4, 3, and 2, and Celeron processors, as well as Advance Micro Devices' K6-3 and -2 chips. The data are for two points in time, namely April 111999 and March 4 2001, and are listed in Table 3.

Table 3: Processor price data

\begin{tabular}{ccccccc}
\hline \hline \multicolumn{3}{c}{$04 / 11 / 1999$} & & & \multicolumn{3}{c}{$03 / 04 / 2001$} \\
processor & $\begin{array}{c}\text { speed } \\
\text { MHz }\end{array}$ & price & & processor & $\begin{array}{c}\text { speed } \\
\mathrm{MHz} / \mathrm{GHz}^{*}\end{array}$ & price \\
\cline { 1 - 2 } \cline { 5 - 6 } P-III & 500 & 637 & & P-IV & $1.5^{*}$ & 637 \\
P-III & 450 & 411 & & P-IV & $1.4^{*}$ & 413 \\
P-II & 450 & 396 & & P-IV & $1.3^{*}$ & 332 \\
P-II & 400 & 234 & & P-III & $1.0^{*}$ & 241 \\
P-II & 350 & 163 & & P-III & 933 & 225 \\
Celeron & 433 & 143 & & P-III & 800 & 165 \\
Celeron & 400 & 103 & & Celeron & 800 & 112 \\
Celeron & 366 & 73 & & Celeron & 766 & 103 \\
Celeron & 333 & 67 & & Celeron & 733 & 83 \\
K6-3 & 450 & 397 & & & & \\
K6-3 & 400 & 237 & & & & \\
K6-2 & 475 & 213 & & & & \\
K6-2 & 350 & 68 & & & \\
K6-2 & 333 & 62 & & & \\
\hline \hline
\end{tabular}

\footnotetext{
${ }^{8}$ Electronic Engineering Times, April 19, 1999, "Intel, AMD Slash Processor Prices" and IDG News Service, "Intel Trims Prices on Desktop PC Chips", March 05, 2001.
} 